\title{
2 ints

THE EFFECT OF PHOTOCHEMICAL MODELS

ON CALCULATED EQUILIBRIA AND COOLING RATES

IN THE STRATOSPHERE

(NASA-CR-132777) THE EFFECT OF

PHOTOCHEMICAL MODELS ON CALCULATED

EQUILIBRIA AND COOLING RATES IN THE STRATOSPHERE (Chicago oniv.) 90 HC $\$ 6.50$

\section{Donna Blake}

The Florida State University.

Tallahassee, Florida

and

Richard S. Lindzen ${ }^{1}$

Harvard University

Camb ridge, Massachusetts

1 Alfred P. Sloan Foundation Fellow

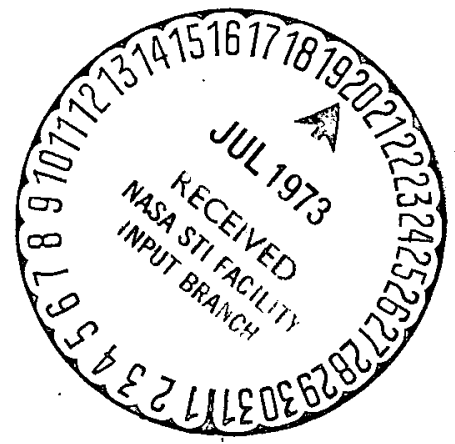


ABSTRACT

Simplified models are developed for radiative heating and cooling, and for ozone photochemistry in the region 22-60 km. The latter permit the inclusion of nitrogen and hydrogen reactions in addition to simple oxygen reactions. The simplicity of the scheme facilitates the use of a wide variety of cooling and reaction rates. We also consider determination of temperature and composition as a joint process. It is. shown that joint radiative-photochemical equiliorium is appropriate to the mean state of the atmosphere between 35 and $60 \mathrm{~km}$. Equilibrium calculations are then used to show that hydrogen reactions are inportant for ozone and temperature distributions primarily above $40 \mathrm{~km}$ while nitrogen reactions are important primarily bejow $50 \mathrm{~km}$. Comparisons with observed distributions of temperature and ozone suggest the need for water vapor mixing ratios of from $0.5-2.5 \times 10^{-6}$ and rixing ratios of $\left(\mathrm{irO}_{2}+\mathrm{NO}\right)$ of from $2 \times 10^{-8}-1.6 \times 10^{-7}$ at the stratopanse. At $35 \mathrm{~km}$, a mixing ratio of $\left(\mathrm{NO}_{2}+\mathrm{NO}\right)$ of about $3 \times 10^{-8}$ is indicated. The precise values depend on our choice of reaction and radiative cooling rate coefficients, and the simple formulation permits the reader to check the effect of new rates as they become available.

The relaxation of perturbations from foint radiative-photocirenical equilibrium is also investigated. In all cases the coupling between temperature dependent ozone photochemistry and radiation lead to a reduction of the themal relaxation the from its purely radiative value. The latter, which amounts to about 10 days, is reduced to $2-4$ days at heights of $31-35 \mathrm{~km}$. This greatly enhances the dissipation ot waves travelltiig through the stratosphere. 


\section{INTRODUCTION}

The equilibrium temperature in the stratosphere is determined by the approximate balance between heating due to absorption of solar ultraviolet energy by ozone and cooling due to infrared emission by the $15 \mu$ band of carbon dioxide. (A certain amount of cooling is also due to $\mathrm{O}_{3} 9.6 \mu$ emission, but this cooling is considerably less than that due to the $15 \mu$ band of $\mathrm{CO}_{2}$ [Murgatroyd and Goody 1958]). The rate of energy absorption and therefore the temperature depend on the ozone density.

Production of ozone is by the reaction

$$
\mathrm{O}+\mathrm{O}_{2}+\mathrm{M} \rightarrow \mathrm{O}_{3}+\mathrm{M}
$$

which is strongly temperature dependent. This coupling between tem:perature and ozone density indicates that the relaxation time of a tempèrature perturbation should not be that due to carbon dioxide cooling alone but should be that due to carbon dioxide cooling modified by the effects of photochemistry.

Lindzen and Goody (1965) have calculated the thermal relaxation time for carbon dioxide cooling coupled with photochemical effects for a pure oxygen atmosphere. Since these calculations were made, the rates for pure oxygen reactions have been questioned and alternative rates have been proposed. In addition it now seems that reactions involving nitrogen and hydrogen compounds may besignificant in determining the ozone distribution in the stratosphere. 
(Hunt 1966, Leovy 1969a, Crutzen 1971) and such reactions should therefore be included in the photochemical model. Most of the rates for reactions involving hydrogen compounds are not temperature dependent so there is a question as to the influence of these reactions on the coupling between ozone density and temperature. It has been suggested (Leovy 1969a) that if the hydrogen reactions are dominant in determining the ozone density tinen the appropriate thermal relaxation time is just that due to cooling from the $15 \mu$ carbon dioxide band. As we shall show, this is untrue since relation (1) remains important in all schemes. Cooling due to infrared emission by carbon dioxide and modified by photochemistry acts as damping on motions in the stratosphere. The time scale for this damping, which may be represented as ivewtonian cooling, is simply the thermal relaxation time scale. As Dickinson (1969) shows, intemal Rossby waves, excited in the troposphere, could carry large amounts of energy up to the lower atmosphere unless this time is much less than ten days, ten days being the approximate time scale for unmodified $\mathrm{CO}_{2} 15 \mu$ cooling. Thus, the effects of photochemistry on this time scale could be crucial. 
In this paper we shall investigate the effect of photochemistry on the coling rate for the height range $22-61 \mathrm{~km}$. A simplified photochemical model that is suitable for this height range and that includes reactions involving nitrogen and hydrogen compounds is developed in section 2 . The temperature equation for this photochemical model is obtained in section 3 . Vertical distributions of con:tituents and temperature for radiative-photochemical equilibrium are discussed in section 4. Linearized equations for the photochemistry 
and temperature are found in section 5 as are the relevant time scales for photochemical and thermal relaxation. Conclusions ane presented in section 6 .

Many reaction rates are uncertain by as much as an orde of magnitude so a wide range of values is used. Because mixing ratios for water vapor and nitrogen oxides are uncertain several distributions are used. For the range of rates and ratios used, it is found that the effect of including photochemistry is to reduce the thermal relaxation time scale above $30 \mathrm{~km}$ from the value appropriate when only infrared emission by carbon dioxide is considered. Furthermore, the minimum value for the thermal relaxation time scale always occurs at heights between 31 and $35 \mathrm{~km}$ and with values between two and four days.

- It is also found that equilibrium distributions of temperature and ozone density vary with the different rates and ratios assumed. At the stratopause relaxation time scales are short enough $(\sim 90$ minutes for ozone and a few days for temperature) that the equilibrium temperature should be close to the observed temperature of approximately $270^{\circ} \mathrm{K}$ (Supplemental Atmosphere [Tropical], Theon and Smith 1971). We attempt to match the observed temperature rather than the observed ozone densities since the former is better determined than the latter between 35 and $61 \mathrm{~km}$. 
The neglect of nitrogen and hydrogen reactions leads to the prediction of excessive temperatures between 35 and $61 \mathrm{~km}$. The prediction of observed temperatures between 50 and $61 \mathrm{kn}$ calls for water vapor mixing ratios of from $0.5-3 \times 10^{-6}$ depending on the reaction rates used. A mixing ratio for total nitrogen oxides $\left(\mathrm{NO}+\mathrm{NO}_{2}\right)$ of $2-3 \times 10^{-8}$ produces correct temperatures from $35-50 \mathrm{~km}$. All such estimates depend on our choice of reaction and cooling rate coefficients, but the dependence has been specified in a simple manner. 


\section{PHOTOCHEMICAL MODEL}

As many as 80 different ieactions have been considered for an atmosphere consisting of nitrogen, hydrogen, oxygen, and their compounds (Hunt 1966, Shimazaki and Laird 1970, Crutzen 1971). For many problems the full set of reactions may not be needed and a much shorter set can be used for the photochemical model. It should be apparent that the simplified photochemical model dereloped in this section may not be the most suitable one for all problems.

For the current problem we are interested primarily in the vertical distribution of ozone, the reactions which determine this distribution, and the temperature dependence of such reactions for the height range, $22-61 \mathrm{~km}$. Many reactions are important in only limited height ranges. Reactions which are important only above $61 \mathrm{~km}$ or below $22 \mathrm{~km}$ are not retained. The list of reactions retained is in Table 1.

For each constituent found in Table 1 it is possible to write a continuity relation

$$
\frac{d n_{i}}{d t}+n_{i} \vec{\nabla} \cdot \vec{v}=\dot{S}_{i}-L_{i}
$$

where $d / d t$ is the substantive derivative, $\frac{\lambda}{\partial t}+\vec{v} \cdot \vec{\nabla}, \vec{v}$ is the velocity vector, and $n_{i}, S_{i}$, and $L_{i}$ are the number density, source term and loss term, respectively, of the constituent $i\left(i=O\left(O\left(^{3} \mathrm{P}\right), \mathrm{O} *\left(O{ }^{1} D\right)\right)\right.$, 
$\mathrm{HO}_{2}, \mathrm{OH}, \mathrm{H}, \mathrm{H}_{2} \mathrm{O}, \mathrm{H}_{2} \mathrm{O}_{2}, \mathrm{HNO}_{3}, \mathrm{HNO}_{2}, \mathrm{NO}, \mathrm{NO}_{2}$, and $\mathrm{NO}_{3}$ ). Below

$70 \mathrm{~km}$

$$
n_{i} / n_{m}<1
$$

where $\mathrm{n}_{\mathrm{m}}$ is the molecular number density, so the continuity equation for $\mathrm{n}_{\mathrm{m}}$ becomes

$$
\frac{d}{d t} n_{m}+n_{m} \vec{\nabla} \cdot \vec{v}=0
$$

Substituting eq (4) into eq (2) yields

$$
\frac{\mathrm{dn}_{i} / \mathrm{n}_{\mathrm{m}}}{\mathrm{dt}}=\left(\mathrm{S}_{i}-\mathrm{L}_{i}\right) / \mathrm{n}_{\mathrm{m}}
$$

The ratio $n_{i} / n_{m}$ for a constituent $i$ is referred to as its mixing ratio. The photochemical model now consists of 13 continuity equations of the form (5). There are several relations among the constituents which will further simplify the model. Some of these relations have been pointed out previously (Ditsch 1968, Leovy 1969a, and Crutzen 1971).

Since below $61 \mathrm{~km}$ less than $1 \%$ of the $\mathrm{H}_{2} \mathrm{O}$ molecules are dissociated in a day by reactions (3) and (8), the mixing ratio of water vapor at a given height may be considered constant. Also the adjustment time for equilibrium of $O *$ is $t(O *)=\left(k_{7}{ }^{n} m^{-1}<10^{-5} \mathrm{sec}\right.$ and. that for $\mathrm{H}$ is $t(\mathrm{H})=\left(\mathrm{n}_{\mathrm{O}}{ }^{\mathrm{n}} \mathrm{m}^{\mathrm{k}}{ }_{10}\right)^{-1} \cdot(4 \cdot \mathrm{sec}$. Both of these 
constituents may be considered in equilibrium with concentrations

$$
\mathrm{n}_{0 *} \approx \frac{\mathrm{q}_{3 b^{\mathrm{n}_{0}}}}{\mathrm{k}_{7} \mathrm{n}_{\mathrm{m}}}
$$

and

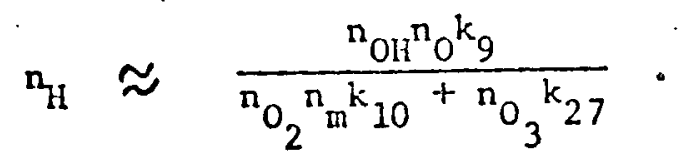

As Leovy (1969a) Indicates, eq (7) means that when reaction (27) is small compared to reaction $(10)$, the atomic hydrogen produced in reaction (9) is destroyed so rapidjy by reaction (10) that the two reactions may be replaced by the single reaction

$$
\mathrm{OH}+\mathrm{O} \rightarrow \mathrm{HO}_{2}
$$

with the reaction rate, $k_{9}$. This approximation is valid bclow $40 \mathrm{~km}$ but about $5 \%$ of the hydrogen destruction at $40 \mathrm{~km}$ is by reaction (27) and above this height reaction (27) becomes increasingly important to the destruction of hydrogen and ozone, accounting for $20 \%$ at $60 \mathrm{~km}$. Thus, if reaction rates are significantly alterred, reaction (27) could. become a major one. 
When the reactions involving $O$ and $O_{3}$ are considered, it is apparent that the dominant reactions involve interconversion between 0 and $\mathrm{O}_{3}$. The ratio

$$
R_{1}=\frac{n_{0}}{n_{0_{3}}} \approx \frac{q_{3 a}+q_{35}}{n_{0_{2}} n_{m 5}^{k_{5}}}
$$

has an adjustment time, $t\left(R_{1}\right)=\left(q_{3 a}+q_{3 b}+n_{0_{2}} n_{m} k_{5}\right)^{-1}<10^{2}$ sec, which is short compared to other time scales of interest so en (9) remains valid. Similarly the reactions involving interconversicn between $\mathrm{HO}_{2}$ and $\mathrm{OH}$ are dominant among those involving these two constituents. Below $40 \mathrm{~km}$, where (8) may be used 


$$
R_{2}=\frac{n_{H_{2}}}{n_{O H}} \approx \frac{n_{0} k_{9}+n_{O_{3}}{ }^{k} 12}{n_{0} k_{11}+n_{N O} k_{15}}
$$

which has an adjustment time of $t\left(R_{2}\right)^{\circ}=\left(n_{0} k_{9}+n_{0_{3}} k_{12}+n_{0} k_{11}+\right.$ $\left.\mathrm{n}_{\mathrm{NO}} \mathrm{k}_{15}\right)^{-1}<100 \mathrm{sec}$. Above $40 \mathrm{~km}$

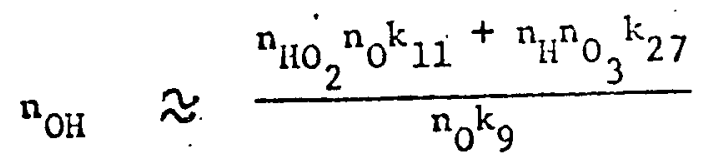

and

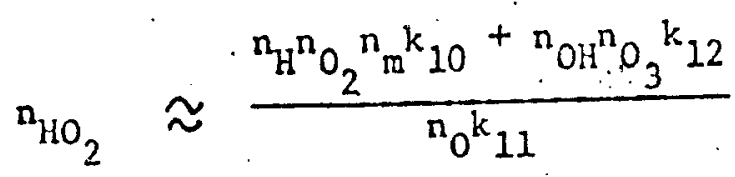

which have adjustment times $t(\mathrm{OH})=\left(n_{0} k_{9}\right)^{-1}<15 \mathrm{sec}$. and $t\left(\mathrm{HO}_{2}\right)=$ $\left(n_{0} k_{11}\right)^{-1}<15$ sec. Therefore, when eq (7) is used in eq (12) the resulting ratio is

$$
\begin{aligned}
& R_{2}=\frac{n_{H_{2}}}{n_{O H}} \approx \frac{k_{9}}{k_{11}} \cdot\left(1+\frac{\mathfrak{n}_{O_{3}}{ }^{k} 27}{n_{O_{2}}{ }^{n}{ }^{k} \cdot 10}\right)^{-1} . \\
& +\frac{k_{12}}{R_{1} k_{11}}
\end{aligned}
$$

The term $\frac{k_{12}}{k_{1} k_{11}}$ in (13) becomes negligibly snall above $45 \mathrm{~km}$. Finally, by simflar arguments, one gets a ratio,

$$
R_{3}=\frac{n_{\mathrm{NO}}}{n_{\mathrm{NO}_{2}}} \approx \frac{\mathrm{n}_{0} \mathrm{k}_{16}+\mathrm{q}_{\mathrm{NO}}}{\mathrm{n}_{3}{ }^{\mathrm{k}} 17}
$$


which has an adjustment time $t\left(\mathrm{R}_{3}\right)=\left(\mathrm{n}_{\mathrm{O}} \mathrm{k}_{16}+\mathrm{q}_{\mathrm{NO}_{2}}+\mathrm{n}_{\mathrm{O}_{3}} \mathrm{k}_{17}\right)^{-1}<200 \mathrm{sec}$. The three constituents, $\mathrm{HNO}_{3}, \mathrm{HNO}_{2}$, and $\mathrm{NO}_{3}$ are approximately in equilibrium with values of

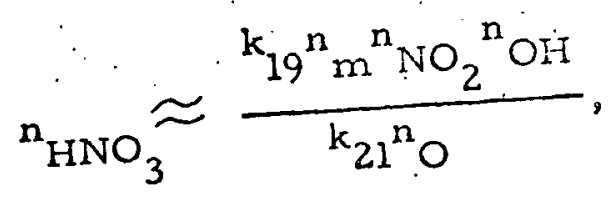

$$
\begin{aligned}
& \mathrm{n}_{\mathrm{HNO}} \underset{2}{\approx} \frac{\mathrm{k}_{20^{n} m^{\mathrm{n}} \mathrm{OH}^{\mathrm{n}} \mathrm{NO}}}{\mathrm{k}_{22} 2^{\mathrm{n}_{\mathrm{O}}}}
\end{aligned}
$$

and

$$
\frac{\mathrm{k}_{21}{ }^{\mathrm{n}} \mathrm{O}^{\mathrm{n}} \mathrm{HNO}_{3}+\mathrm{k}_{18}{ }^{\mathrm{n}} \mathrm{NO}_{2}{ }^{\mathrm{n}} \mathrm{O}_{3}}{\mathrm{k}_{23^{\mathrm{n}} \mathrm{NO}}}
$$

Their adjustment times are: $\tau\left(\mathrm{HNO}_{3}\right)=\left(\mathrm{k}_{21} \mathrm{n}_{\mathrm{O}}\right)^{-1}<2 \cdot 10^{3} \mathrm{sec}$, $\tau\left(\mathrm{HNO}_{2}\right)=\left(\mathrm{k}_{22} \mathrm{n}^{\mathrm{O}}\right)^{-1}\left(2 \cdot 10^{3} \mathrm{sec}\right.$ and $\tau\left(\mathrm{NO}_{3}\right)=\left(\mathrm{k}_{23} 3^{\mathrm{n}} \mathrm{NO}^{)^{-1}}<2 \cdot 10^{3} \mathrm{sec}\right.$. These times may be sufficiently long for the use of equilibrium values 
to be questioned. However, eqs (15), (16), and (17) perait an estimate of the densities of $\mathrm{HNO}_{3}, \mathrm{HNO}_{2}$, and $\mathrm{NO}_{3}$ relative to the densities of $\mathrm{NO}$, $\mathrm{NO}_{2}$, $\mathrm{HO}$ and $\mathrm{HO}_{2}$. These estimates indicate that the constituents $\mathrm{MNO}_{3}$, $\mathrm{HNO}_{2}$, and $\mathrm{NO}_{3}$ are of minor importance in determining the vertical distribution of $\mathrm{O}_{3}$. Therefore eqs (15), (16), and (17) are valid approximations for the present problem.

The total odd nitrogen density is the sum of the densities of NO, $\mathrm{NO}_{2}, \mathrm{NO}_{3}, \mathrm{HNO}_{2}$ and $\mathrm{HNO}_{3}$. Since the list of reactions in Table 1 does not contain sources or losses for the total odd nitrogen density. the continuity equation is

$$
\frac{d}{d t} \frac{\left[n_{N O}+n_{N_{2}}+n_{N_{3}}+n_{H_{N}}+n_{\mathrm{HNO}_{2}}\right]}{n_{m}}=0
$$

or, using eqs (15), (16), and (17) in eq (18), one gets

$$
\frac{d}{d t} \frac{\left[\mathrm{nO}_{\mathrm{NO}}+\mathrm{n}_{\mathrm{NO}}\right]}{n_{\mathrm{m}}}=0
$$

Two sources for total odd nitrogen in the region $22-61 \mathrm{~km}$ are considered to be downward diffusion of NO from above $70 \mathrm{~km}$ where it is formed and the upward diffusion of $\mathrm{N}_{2} \mathrm{O}$ from the troposphere, which is then destroyed by the reaction

$$
\mathrm{N}_{2} \mathrm{O}+\mathrm{O} * \rightarrow 2 \mathrm{NO}
$$


with a rate $k=9 \times 10^{-11} \operatorname{cm}^{3} \sec ^{-1}$ (Donovan and Husain 1970). Now the mixing ratio of $\mathrm{N}_{2} \mathrm{O}$ is $2.5 \times 10^{-7}$ at the tropopause and apparently decreases with height (Schutz et al. 1970). If we estimate the mixing ratio of $\mathrm{NO}+\mathrm{NO}_{2}$ as $10^{-9}-10^{-7}$ (Junge 1963, Barth 1966, Pearce 1969), then the time scale for an increase in odd nitrogen density duc to the two sources described is estimated to be several weeks. The possible losses to the odd nitrogen density are downward diffusion of the constituents or conversion to $\mathrm{N}_{2} \mathrm{O}_{5}$ followed by downward diffusion of that constituent.

Rather than try to include the source and loss terms for the odd nitrogen concentration, we have decided to use eq (16) or, equivalentiy, to set

$$
\left(\mathrm{n}_{\mathrm{NO}}+\mathrm{n}_{\mathrm{NO}_{2}}\right) / \mathrm{n}_{\mathrm{m}}=\mathrm{K}
$$

where $K$ is a mixing ratio which is constant in time but a possible function of height. This highly simplified treatment of the nitrogen constituents may be justified on the grounds that we are not seeking a detailed time and height distribution for each nitrogen constituent but are trying to evaluate the importance of the nitrogen reactions to the distribution of ozone.

The constituent $\mathrm{H}_{2} \mathrm{O}_{2}$ is produced in reaction (24) and destroyed in reactions (25) and (26). The nei result is the loss of $\mathrm{HO}_{2}$ back into $\mathrm{H}_{2} \mathrm{O}$. This conversion also occurs in reaction (14). If reactions 
(24), (25), and (26) are neglected the resuit is that the sum, ${ }^{\mathrm{OHI}}+\mathrm{n}_{\mathrm{HO}_{2}}$ ' calculated is too large. However, the change in the sum, $\mathrm{n}_{\mathrm{OH}}+\mathrm{n}_{\mathrm{HO}}{ }_{2}$ ' occurring when these reactions are ignored, is significant only below $35 \mathrm{~km}$. It will be shown in sections 4 and 5 that the reactions involving hydrogen are significant only above $40 \mathrm{~km}$. Therefore, reactions (24), (25), and (26) are to be neglected.

The constituents $\mathrm{O}, \mathrm{H}, \mathrm{HNO}_{3}, \mathrm{HNO}_{2}$, and $\mathrm{NO}_{3}$ are considered to be in equilibrium (eqs (6), (7), (15), (16), and (17) and the water vapor mixing ratio is considered constant in time while $\mathrm{H}_{2} \mathrm{O}_{2}$ is neglected. Therefore, the continuity relations, eq (3), are needed for only the six constituents, $\mathrm{O}, \mathrm{O}_{3}, \mathrm{NO}, \mathrm{NO}_{2}, \mathrm{HO}$, and $\mathrm{HO}_{2}$. By using eqs (9), (10), and (14), the six continuity relations are reduced to three:

$$
\begin{aligned}
& \frac{d}{d t}\left(I+R_{1}\right) \varphi=C-A_{\varphi}^{2}-B \varphi \psi-F \varphi x \\
& \frac{d}{d}\left(1+R_{2}\right) \psi=D \varphi+G-E \psi^{2},
\end{aligned}
$$

and

$$
\frac{d}{d t}\left(1+R_{3}\right) X=0
$$

where $\varphi \equiv \mathrm{n}_{\mathrm{O}} / \mathrm{n}_{\mathrm{m}}$

$$
\begin{aligned}
\psi & \equiv \mathrm{n}_{\mathrm{OH}} / \mathrm{n}_{\mathrm{m}} \\
\mathrm{x} & \equiv \mathrm{n}_{\mathrm{NO}_{2}} / \mathrm{n}_{\mathrm{m}}
\end{aligned}
$$

with 


$$
\begin{aligned}
& c=2 q_{2}{ }^{n} o_{2} / n_{m} \\
& A=2 k_{1} k_{6}{ }^{n} \\
& B=\left(R_{1} k_{9}+R_{1} R_{2} k_{11}+k_{12}\right) n_{m} z \approx 40 k m \\
& B=\left(R_{1} k_{9}+R_{1} R_{2} k_{11}+R_{1} k_{9}\left(I+\frac{n_{0_{2}}{ }^{n}{ }^{k}{ }_{10}}{n_{0_{3}}{ }^{k}{ }_{27}}\right)^{-1}\right.
\end{aligned}
$$

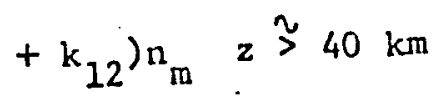

$$
\begin{aligned}
& F=\left(2 R_{1} k_{16}+k_{18}\right) n_{m} \\
& \dot{D}=2 k_{8} n_{H_{2}}{ }^{q_{3 b}} / k_{7} n_{m}
\end{aligned}
$$

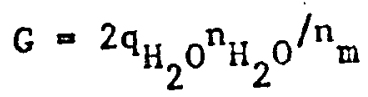

$$
\begin{aligned}
& E=2\left(k_{13}+R_{2} k_{14}\right) n_{m} \text {. }
\end{aligned}
$$

Using (13) in (28) we get

$$
\text { B } \approx 2\left(R_{1} k_{9}+k_{12}\right) n_{m}
$$

Had we formally retained (27) above $40 \mathrm{~km}$, then we would also obtain (33) as an approximation. Thus (27) may be used at all heights with only small errors. As with eq (13), $k_{12}$.in (33) may be neglected above $45 \mathrm{~km}$.

Eqs (6), (7), (9)-(17), and (22)-(32) together with the reaction rates in Table 1 comprise the photochemical model to be used in sections 3,4 , and 5 . 


\section{ENERGY REIATION}

\section{The energy relation is}

$$
\rho c_{v} \frac{d T}{d t}=s+p \vec{\nabla} \cdot \vec{v}
$$

where $\mathrm{p}=$ pressure, $\mathrm{T}=$ temperature, $\rho=$ density, $\mathrm{c}_{\mathrm{v}}=$ heat capacily at constant volume. Here

$$
S \equiv \hat{E}+C
$$

where $\hat{E}$ represents energy absorbed and $C$ is the heat exchange due to infrared radiation. In the atmosphere the fractional pressure change is small for velocities less than that of sound (Jefferys 1930). This permits eq (34) to be approximated by

$$
\frac{d T}{d t}+w \frac{g}{c_{p}}=\frac{1}{\rho c_{p}}(\hat{E}+C)
$$

where $c_{p}=$ heat capacity at constant pressure, $g=$ gravitational constant and $w$ is the vertical velocity. (See Ogura and Phillips, 1962, for an analysis of the validity of (31); llolton, 1971, shows that (31) is rigorously correct in a coordinate system where $\log$ p replaces z.) As discussed in the introduction the major source of cooling in the region 22-61 $\mathrm{kn}$ is the $15 \mu$ band of carbon dioxide. This cooling is proportional to the local blackiody function (Rodgers and Walshaw, 1966) which, for tine range of temperatures found in the stratosphere, 
can be approximated as a linear function of temperature. Thus, the cooling or thermal emission, is

$$
\frac{1}{\rho c_{p}} \mathrm{C} \approx-\mathrm{a}\left(\mathrm{T}-180^{\circ}\right)
$$

where $a$ is a function of height. We use two different distributions of a: (1) $a=(17 \text { days })^{-1}$ (Lindzen and Goody 1965$)$ and (2) $a=(10 \text { days })^{-1}$, z $35 \mathrm{~km}, \mathrm{a}=(10 \text { days })^{-1}\left(1+\frac{z-35}{20}\right), \mathrm{z}\langle 35 \mathrm{~km}$, (Dickinson 1968). These two distributions, referred to as slow and fast infrared cooling respectively, offer a range of cooling rates. They show the effect that changing the infrared cooling rate has on the stratos pheric temperature and ozone distributions. Lore recently Dickinson (1972, personal communication) has suggested that ' $a$ ' continues to increase above $35 \mathrm{~km}$.

The energy source may be written as

$$
\hat{E}=\sum_{l} r_{l} \cdot \varepsilon_{l}
$$

where $r_{l}$ is the number of reactions per sec per $\mathrm{cm}^{3}$ for reaction $\ell$ and $\epsilon_{\ell}$ is the energy gain per reaction. The $\epsilon_{l}$ consists of dissociation energy, $D_{2}$, and solar energy absorbed, $E_{Z} \cdot$ With these definitions eq (33) becomes

$$
\hat{E}=\sum_{l} r_{2}\left(E_{2}+D_{2}\right) \text {. }
$$

Solar energy absorbed by $\mathrm{O}_{3}, \mathrm{O}_{2}, \mathrm{H}_{2} \mathrm{O}$ and $\mathrm{NO}_{2}$ contributes to the source terms: 


$$
\begin{aligned}
& \sum_{l} x_{l} \quad E_{l}=h \bar{v}_{O_{2}} q_{2}{ }^{n} o_{2}+h \bar{v}_{O_{3}}\left(q_{3 a}+q_{3 b}\right){ }^{n} o_{3} \\
& +h \bar{\nu} \mathrm{NO}_{2}{ }^{q_{\mathrm{NO}}}{ }_{2}^{\mathrm{n}} \mathrm{NO}_{2} \\
& +\bar{h}_{\mathrm{\nu}_{2} \mathrm{O}} \mathrm{O}_{\mathrm{H}_{2}} \mathrm{O}^{\mathrm{n}} \mathrm{H}_{2} \mathrm{O}
\end{aligned}
$$

where

$q_{j}(z)=\int a_{j o \nu} \exp \left(-\sum_{j} a_{j} x_{j}\right) d \nu, j=O_{2}, O_{3}, \mathrm{HO}_{2}, \mathrm{NO}_{2}$

and

$\nu_{j}=q_{j}^{-1} \int a_{j} \nu I o \nu \exp \left(-\sum_{j} a_{j} x_{j}\right) \dot{d} \nu$

Fere $a_{j}(\nu)$ is the absorption cross section in $\mathrm{cm}^{2}$ of the $j^{\text {th }}$ constituent, $I_{o v}$ is the photon flux incident at the top of the atmosphere, $x_{j}$ is the total number of molecules per $\mathrm{cm}^{2}$ of the $j^{\text {th }}$ constituent between the top of the atmosphere and the altitude $z, h$ is the Planck constant and $\bar{\nu}_{j}$ is the mean frequency of solar photons absorbed by the $j^{\text {th }}$ constituent. Representative variations of $\left(q_{3 a}+q_{3 b}\right){ }^{n} O_{3},{ }^{9} O_{2}{ }^{n} O_{2}, q_{H_{2}} O^{n} \cdot H_{2} O$ and $\mathrm{q}_{\mathrm{NO}_{2}}{ }^{\mathrm{n}} \mathrm{NO}_{2}$ with height are shown in Figure 1. It is apparent that

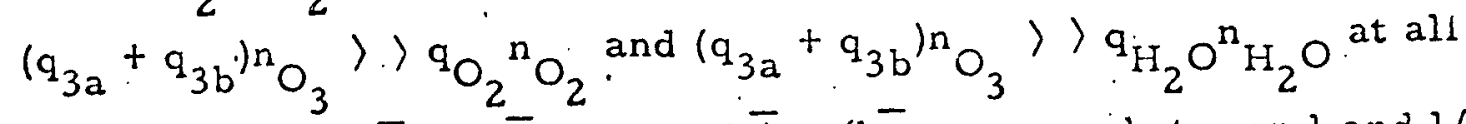
heights. Since $\mathrm{h}_{\overline{\mathrm{v}}} \overline{\mathrm{O}}_{3} / \mathrm{h}^{\prime} \mathrm{H}_{2} \mathrm{O}$ and $\mathrm{h} \bar{\nu}_{\mathrm{O}_{3}} / \mathrm{h} \bar{\nu}_{\mathrm{H}_{2} \mathrm{O}}$ vary between $\mathrm{l}$ and $\mathrm{l} / 3$, the term hiv $\bar{\nu}_{3}\left(q_{3 a}+q_{3 b}\right){ }^{n} O_{3}$ is much larger than $h \bar{\nu}_{\mathrm{H}_{2}} \mathrm{O}^{\mathrm{q}_{\mathrm{Fi}}} \mathrm{O}^{\mathrm{n}} \mathrm{H}_{2} \mathrm{O}$ or $\mathrm{h}^{2} \mathrm{O}_{2}{ }^{\mathrm{q}} \mathrm{O}_{2}{ }^{\mathrm{n}} \mathrm{O}_{2}$ at all heights. The latter two terms may be neglected 
in eq $(40)$. Above $\left.30 \mathrm{~km} \mathrm{~h} \bar{\nu}_{3}\left(\mathrm{q}_{3 a}+\mathrm{q}_{3 b}\right) \mathrm{n}_{3}\right\rangle \mathrm{h}_{\mathrm{\nu}_{2}} \mathrm{NO}_{2} \mathrm{q}_{\mathrm{NO}_{2}}{ }^{\mathrm{n}} \mathrm{NO}_{2}$. Below $30 \mathrm{~km}$, the ratio $\left(q_{3 a}+q_{3 b}\right){ }^{n} O_{3} / q \mathrm{NO}_{2}{ }^{n} \mathrm{NO}_{2} \geq 8$, provided the mixing ratio of $\mathrm{NO}_{2}$ does not exceed $3 \cdot 10^{-8}$ (the value used in calculating $\mathrm{q}_{\mathrm{NO}_{2}: \mathrm{NO}_{2}}^{\mathrm{n}}$ for. Figure 1). Since h: $\bar{\nu}_{\mathrm{O}_{3}} / \mathrm{h}_{\overline{\mathrm{v}}} \mathrm{NO}_{2} \approx 0.7$ below $30 \mathrm{~km}$, the term hiv $\bar{v}_{3}\left(q_{3 a}+q_{3 b}\right) \mathrm{n}_{3}>\bar{h}_{\mathrm{HO}_{2}}{ }^{\mathrm{q}} \mathrm{NO}_{2}{ }^{\mathrm{n}} \mathrm{NO}_{2}$ at all heights and the latter term is neglected in eq $(40)$. Then eq $(40)$ becomes

$$
\sum_{l} r_{l} \quad E_{l} \approx \bar{h}_{\nu_{0} O_{3}}\left(q_{3 a}+q_{3 b}\right) n_{m} \varphi \text {. }
$$

The second part of the energy source term in eq (39) can be written as

$$
\begin{aligned}
& \sum_{l} r_{l} \quad D_{l} \vdots=D\left(O_{3}\right) n_{m} \frac{{ }^{d n} O_{3} / n_{m}}{d t}-\frac{1}{2} D\left(O_{2}\right) n_{m} *\left(\frac{d}{d t} n_{O} / n_{m}+\frac{d}{d t} n_{O_{3}}^{\prime} m^{\prime}\right. \\
& +D\left(\mathrm{HO}_{2}\right) \mathrm{n}_{\mathrm{m}} \frac{\mathrm{dn}_{\mathrm{HO}_{2}}{ }^{\mathrm{n}} \mathrm{m}}{\mathrm{dt}}+\frac{1}{2} \mathrm{D}(\mathrm{OH}) \mathrm{n}_{\mathrm{m}}\left(\frac{\mathrm{dn}_{\mathrm{OH}} / \mathrm{n}}{\mathrm{dt}}-\frac{\mathrm{dn}_{\mathrm{HO}} / \mathrm{n}^{\mathrm{m}}}{\mathrm{dt}}\right) \\
& -\frac{1}{2} D\left(\mathrm{H}_{2} \mathrm{O}\right) \mathrm{n}_{\mathrm{m}}\left(\frac{\mathrm{d}}{\mathrm{dt}} \mathrm{n}_{\mathrm{HO}_{2}} / \mathrm{n}_{\mathrm{m}}+\frac{\mathrm{dn} \mathrm{OH}^{/ \mathrm{n}}}{\mathrm{dt}}+\mathrm{D}\left(\mathrm{NO}_{2}\right) \mathrm{n}_{\mathrm{m}} \frac{\mathrm{d}}{\mathrm{dt}}\left(\frac{\mathrm{nO}_{2}}{\mathrm{n}_{\mathrm{m}}}\right)\right.
\end{aligned}
$$

where $D(j)$ is the dissociation energy of the $j^{\text {th }}$ constituent. We have evaluated (44) in detail and have found that its contribution is always small. We will mercifully spare the reader from the specifics. (N. B.: (44) is identically zero for equilibrium.) 
Thus eq (3i) becomes

$$
\frac{d T}{d z}+w \frac{g}{c_{p}}=n \phi-a\left(T-180^{\circ}\right)
$$

where

$$
n \equiv h \bar{v}_{0_{3}}\left(q_{3 a}+q_{3 b}\right) n_{m} / \rho c c_{p}
$$




\section{RADIATIVE-PHOTOCHEIICAL EQUILTBRIU:A}

The photodissociation rates and energy absorption all vary with the solar zenith angle and thus local changes in temperature and composition have a time scale of a day. The photochemical relaxation time scales are less than a day above 35 kin for all constituents so calculations made. with the local the changes in composition neglected should still give realistic distributions of constituents. However, the thermal relaxation time scale is a minimum of two to three days (see section 5). An estimate of the daily variation in temperature due =o changing zenith angie of the sun can be made. The maximum energy. absorption per day is at $50 \mathrm{~km}$ so the maximum daily variation in terperature rould be expected at this height. At $50 \mathrm{~km}$ the energy absorption rate at noon is about $3 \cdot 10^{-3} \mathrm{ergs} \mathrm{cm}^{-3} \mathrm{sec}^{-1}$. Roughly one half of this energy goes to maintain the mean temperature. The noontime flux f.s, also about half the amplitude of the diurnal oscillation in absorption. Then, from eq (45), the daily variation in temperature is estimated

$$
\frac{\partial(T) d}{\partial t} \approx \frac{(n \phi) d}{\rho c_{p}}-a(T) d
$$

where the subscript $d$ refers to the daily variation and $a=(10 \text { days })^{-1}$, $\dot{\rho}=10^{-6} \mathrm{~g} \mathrm{~cm}^{-3}$, and $c_{p}=10^{7}$ ergs $\left(g^{\circ} \mathrm{K}\right)^{-1}$. Thus $\mathrm{Td} \approx 2 \circ \mathrm{K}$ which is small enough that calculations made with the local temperature change neglected should still give realistic estimates of the temperature. 
In the temperature relation, eq (45), the advective terms are

$$
u \frac{\partial T}{\partial x}+v \frac{\partial T}{\partial y}+w\left(\frac{\partial T}{\partial z}+\frac{\mathcal{L}}{c_{p}}\right)
$$

The stze of the winds and temperature gradients can be estimated from Leovy (1964a and 1964b), who calculated thermally driven circulations In the stratosphere and mesosphere. Between 35 and $61 \mathrm{~km}$ the advective terms are at least an order of magnitude less than the remaining terns. For example, at $50 \mathrm{~km} \frac{\partial \mathrm{T}}{\partial \mathrm{y}} \approx 3 \cdot 10^{-3}{ }^{\circ} \mathrm{K} \mathrm{km}, \frac{\mathrm{dT}}{\mathrm{d} z} \approx 0, \mathrm{v} \approx .6 \mathrm{~m} \mathrm{sec}^{-1}$, $\mathrm{w} \approx .08 \mathrm{~cm} \mathrm{sec}^{-1}$, and $\frac{\mathrm{g}}{c_{\mathrm{p}}}=10^{\circ} \mathrm{K} \mathrm{km}^{-1}$ so the vertical advective term is $\sim 8 \cdot 10^{-6} \circ \mathrm{K} \mathrm{sec}^{-1}$ and the horizontal advective term is

$2 \cdot 10^{-6} \cdot \mathrm{K} \mathrm{sec}{ }^{-1}$. Since the cooling term, a $\left(T-180^{\circ}\right)$, is

$\sim 10^{-4} \mathrm{~K} \mathrm{sec}^{-1}$, the advective terms can be neglected in the temperature equation. Similarly, the advective terms in the continuity equations can be neglected. For example, at 50 km the vertical scale for the ozone mixing ratio is about $24 \mathrm{~km}$, so the time scale for change due to advection is $\sim 3 \cdot 10^{7} \mathrm{sec}$. At $50 \mathrm{~km}$ the ozone relaxation time is $5.4 \cdot 10^{3}$ sec so the advective terms can be neglected. Below $30 \mathrm{~km}$, however, the ozone relaxation time scale increases rapidly to 3. $10^{7} \mathrm{sec}$ while the advective time scale decreases. Therefore, below $30 \mathrm{~km}$ the advective terms are important in determining the ozone distribution in the atmosphere.

The possibility also exists that the tides excited by solar heating could produce mean fluxes of importance to the mean thermodynamic budget. 
Careful checks indicate that this is not the case below $90 \mathrm{~km}$. Thus radiative-photochemical equilibrium seems appropriate from $35-61 \mathrm{~km}$.

For radiative-photochemical equilibrium eqs (22), (23), and (45) become

$$
\begin{aligned}
& 0=C-A \varphi^{2}-B \varphi \psi-F X \varphi \\
& 0=D \varphi+G-E \psi^{2} \\
& 0=-a\left(T-180^{\circ}\right)+n_{\varphi} .
\end{aligned}
$$

The distribution of $\varphi, \psi$, and $T$ with height for equilibrium is found by solving eqs (49), (50), and (51). simultaneously. The solution depends on the mixing ratios of water vapor and the nitrogen oxides and on the values of the rates used for the reactions listed in Table 1.

As indicated in the preceding paragraphs these three equations are valld for the height range $35-61 \mathrm{~km}$. Below this height the photochemical and thermal relaxation time scales beconie long enough that the neglected cerms, particularly the advective terms, should be retained to find temperature and ozone distributions which agree with tirose observed. For convenience, eqs (49), (50) and (51) are lised for the entire height range, $22-61 \mathrm{~km}$, with the stipulation that the resulting radiative-photochemical equilibrium distributions are not cxpected to agree with those observed below $35 \mathrm{~km}$. 
An equilibrium solution also depends on $n, q_{3 a}, q_{3 b}, q_{H_{2}} C^{\prime}$ and $\mathrm{q}_{\mathrm{NO}_{2}}$, which are calculated at each height using eqs. (41), (42), and (46). The spectral region, $1755-3950 \AA$, is divided into thirty-eight frequency intervals and the region, 4750-7000 $\AA$, into four intervals. Below $61 \mathrm{~km}$ nearly all photodissociation of $\mathrm{O}_{2}, \mathrm{O}_{3}, \overline{\mathrm{H}}_{2} \mathrm{O}$, and $\mathrm{NO}_{2}$ is due to absorption of photons in these two spectral regions. Incident photon fluxes, I $v^{\prime}$ are obtained from Kondratyev (1969) for the spectral regions above $3100 \AA$ and from Brinkmann et al. (1966) for the region below $3100 \AA$. It has been suggested (Hinteregger 1970) that the photon fluxes found in Brinkmann et al. (1966) for the spectral region $\therefore$ below $1800 \AA$ may be too large by as much as a factor of three. Below $61 \mathrm{~km}$ the absorption of photons with energies corresponding 
to wavelengths less than $1800 \AA$ makes only a small contribution to dissociation rates of $\mathrm{O}_{2}, \mathrm{O}_{3}, \mathrm{H}_{2} \mathrm{O}$, and $\mathrm{NO}_{2}$. Therefore the question of the magnitude of photon fluxes for the spectral region below $1800 \AA$ is not important for our calculations.

Actual cross sections, $a_{j}$, for absorption by the $j^{\text {th }}$ constituent vary with frequency. For each frequency interval the average cross section, $\bar{a}_{j}$, was used. Cross sections for $\mathrm{O}_{3}$ are from Griggs (1968) and Inn and Tanaka (1953). Those for $\mathrm{H}_{2} \mathrm{O}$ are from Watanabe and Zelikoff (1953) and Thompson et al. (1963). Those for $\mathrm{NO}_{2}$ are from Hall and Blacet (1952) and Nakayama et al. (1959). It is more difficult to determine the appropriate cross section for $\mathrm{O}_{2}$ in a given frequency interval due to the presence of the Schumann-Runge absorption band which has numerous narrow rotation lines. One way of treating the absorption in the Schumann-Runge band is to consider the absorption cross section for $\mathrm{O}_{2}$ as a function of both frequency and path length (Hudson et al. 1969). Then it is possible to divide the atmosphere in layers vertically and calculate the absorption coefficient of a given frequency interval for each layer (Brinkmann 1969). The atmosphere between 61 and $22 \mathrm{~km}$ is divided into twenty-four layers.

The water vapor mixing ratio is not well determined in the stratosphere. Some observations (Mastenbrook 1968, Schölz 1970) indicate a value of $2 \cdot 10^{-6}-3 \cdot 10^{-6}$ at $29 \mathrm{~km}$ and $2 \cdot 10^{-6}-6 \cdot 10^{-6}$ at $50 \mathrm{~km}$. The value of the mixing ratio used at a given height is 
Important at lower heights only if water vapor is a slonficant absorbcr of solar photons or if the hydrogen reactions strongly affect tie ozonc density since ozone is a strong absorber of solar energy. In the height range $22-61 \mathrm{~km}$ the attenuation of incoming solar radiation due to absorption by water vapor is negligible. It is found that hydrogen reactions are dominant in detemining the ozone density above $40 \mathrm{~km} f 0 z$ a water vapor mixing ratio of $5 \cdot 10^{-6}$. The height above which the hydrogen reactions are dominant increases with decreasing water vapo: mixing ratio. Since attenuation of solar encrgy by ozone is smail above $50 \mathrm{~km}$, it is only at heights below this that the vertical distribution of water vapor above is important. "The effect of varying the mixing ratio of water vapor with height is not investigated here. Io: convenience the mixing ratio for watex vapor is assumed to be constant with height and is varied from $0,10^{-8}, 10^{-7}, 10^{-6}, 5 \cdot 10^{-6}$ to $10^{-5}$ for surcessive cases. By this variation we show tive tmportance of witer vapor in determining the vertical distributions of ozone and hence.. temperature.

As indicated in section 2 , the vertical distribution for the mixing ratio of the nitrogen oxides, $\mathrm{NO}$ and $\mathrm{NO}_{2}{ }^{\prime}$, is not well known. However, if downward diffusion of NO from above $70 \mathrm{~km}$ occurs, the mixing ratio of NO must increase with height. The mixing ratio of nitrogen oxides, $\mathrm{K}$, is defined in eq (21), and may be written, by use of eq (14), as

$$
K=\left(1+R_{3}\right) X
$$


$K$ is given two different distributions:

$$
\text { (1) } \begin{aligned}
\mathrm{K} & =3 \cdot 10^{-8} \exp (\mathrm{z}-35) / \mathrm{H} & & z>35 \mathrm{~km} . \\
& =3 \cdot 10^{-8} & & z<35 \mathrm{~km} \\
\text { (2) } \mathrm{K} & =3 \cdot 10^{-9} \exp (\mathrm{z}-35) / \mathrm{H} & & z>35 \mathrm{~km} \\
& =3 \cdot 10^{-9} & & z<35 \mathrm{~km}
\end{aligned}
$$

where $\mathrm{H}=9.25 \mathrm{~km}$. These two distributions are within the range of observations discussed in section 2. They should be helpful in determining the importance of the nitrogen reactions to the ozono and temperature distributions. The terms, nigh nitrogen and low nitrogex, refer to distributions (1) and (2), respectively.

Reaction rates $(5)-(26)$ are uncertain. Three different sets of rates are used for reactions (5) and (6) (the pure oxygen reactions) and these three sets are listed in Table 2 . The rates to use for reactions (7)-(26) are individually increased or decreased by a factor of 10 and the equilibrium distributions of constituents and temperatures are recalculated. It should be noted that the rates for reactions - involving $\mathrm{HWO}_{2}$ are not known. It is assumed that these rates are the same as those for stmilar reactions involving $\mathrm{HNO}_{3}$. This assumption is admittedly a guess which permits an estimate of the numicr density of $\mathrm{HNO}_{2}$. From eq (16) it is found that the number density of $\mathrm{HWO}_{2}$, is sufficiently small that the equilibrium estimate of $\mathrm{HNO}_{2}$ by eq (16) is adequate for the current work. Even if the actual rates for reactions (20) and (22) are such as to increase the numicr density of $\mathrm{HWO}_{2}$ by two orders of magnitude from those estimated in eq (16) using, 
the rates in Table 1 , the effect of $\mathrm{HNO}_{2}$. In the current work could still be treated by usc of eq (16). Since reactions (20) and (22) do not appear in eqs (49), (50), and (51), the rates used for these reactions will not invalidate the calculated temperatures or concentrations unless the actual rates are such that the number density of $\mathrm{HNO}_{2}$ is more than two orders of magnitude larger than estimated. If the actual rates are such that $\mathrm{HNO}_{2}$ number density is more than two orders of magnitude larger than estimated here, the validity of en (16) would have to be reconsidered.

In solving eqs (49), (50), and (51) consideration must be given, to the fact that the thermal emission, as represented in eq (51) by - a (T $\left.-180^{\circ}\right)$, occurs twenty-four hours a day while the absorption of solar energy and photochemistry as given by the other teams in the tinree equations, occur only during the daylight hours. Therefore, in eqs (49), (50), and (51) the terms involving either absorption of solar energy or photochemistry are calculated for their noontine values at the solar equinox and then these values are divided by two. Above $50 \mathrm{~km}$ where absorption does not vary much over the daylight hours, this approximation is fair. However, a.t lower. altitudes it obviously overestimates absorption. That this is the case is shown in time dependent calculations which we w1l mention later; the average temperatures obtained from time dependent calculations are generally $10-15^{\circ} \mathrm{C}$ less than the equilibria calculated here. The thermal emission term is used at its full value because it operates the entire day. Since the rate of 
absorption of solar energy at a given height is also a function of latitude, equilibrium calculations are made at two latitudes: $0^{\circ}$ and $45^{\circ}$.

In Figures 2 and $3\left(0^{\circ}\right.$ latitude $)$ and Figures 4 and $5\left(45^{\circ}\right.$ latitude $)$ are shown the radiative-photochemical distributions of temperature and ozone density for six cases: (1) $O$ (hydrogen and nitrogen reactions neglected), (2) $\mathrm{H}+\mathrm{O}$ (nitrogen reactions neglected), (3) $\mathrm{N}+\mathrm{O}$ (low) (hydrogen reactions neglected), (4) $N+O$ (high) (hydrogen reactions neglected), (5) $\mathrm{N}+\mathrm{H}+\mathrm{O}$ (low), and (6) $\mathrm{N}+\mathrm{H}+\mathrm{O}$ (high). For all six cases the rates in set 1 (Table 2) are used for reactions (5) and (6). and the fast vertical distribution for a. When the hydrogen reactions are included, we use the $5 \cdot 10^{-6}$ ratio for water vapor.

Differences among the six different cases are most striking in the temperature profile (Figures 2 and 4 ). The $O$ case shows a linear increase in temperature up to $45 \mathrm{~km}$ and then a very small decrease in temperature above. The inclusion of the nitrogen reactions (low mixing ratio for nitrogen oxides) decreases the equilibrium tempcrature and ozone density below $30 \mathrm{~km}$ and has little effect on the distributions above $30 \mathrm{~km}$. The effect of the nitrogenreactions is more pronounced. when the high mixing ratio of nitrogen oxides is used. The temperature below $50 \mathrm{~km}$ is considerably reduced $\left(\sim 20^{\circ} \mathrm{K}\right)$ from the pure $O$ case and the ozone density below $40 \mathrm{~km}$ is also considerably reduced $(\sim 40 \%)$. 
Inclusion of the hydrogen reactions has little cffoct below $40 \mathrm{~km}$ but above this height strongly reduces the ozone density and temperature from the values found for the pure $O$ case. When the hydrogen reactions are included, they are dominant in determining the temperature and ozone density above $45 \mathrm{~km}$ even when the nitrogen reactions are also included with either the low or high mixing ratio for nitrogen oxides. Yost significantly, the re appears to be no way of producing a temperature decrease of the observed magnitude above the stratopause without including hydrogen reactions!

Water vapor must be dissociated before the resultant constituents $\mathrm{H}, \mathrm{OH}$, and $\mathrm{HO}_{2}$, can act by means of the hydrogen reactions to reduce ozone density and thus temperature. It might be expected, since the mixing ratio of water vapor is assumed constant with height, that the hydrogen reactions would be important at all heights, not just ajove $40 \mathrm{~km}$. However, the dissociation of water vapor is strongly heightdependent. The photodissociation of water vapor below $61 \mathrm{~km}$ is due to absorption of solar radiation with energies corresponding to wavelengths below $2000 \AA$, which is strongly attenuated below $85 \mathrm{~km}$ due to absorption by $\mathrm{O}_{2}$ and $\mathrm{O}_{3}$. As a result $\mathrm{q}_{\mathrm{H}_{2} \mathrm{O}}$ decreases from $4.3 \cdot 10^{-8}$ $\mathrm{sec}^{-1}$ at $61 \mathrm{~km}$ to $1.1 \cdot 10^{-11} \mathrm{sec}^{-1}$ at $22.5 \mathrm{~km}$. Water vapor is also dis sociated in reaction (8) and the rate of dissociation depends on the density of $O *$. From eq $(6)$ the density of $O *$ is proportional to $q_{3 b}$ 
which is the absorption rate of radiation by ozone below $3100 \AA$. The radiation below $3100 \AA$ is significantly attenuated below $45 \mathrm{~km}$ and $q_{3 b}$ decreases from $8 \cdot 10^{-3} \mathrm{sec}^{-1}$ at $45 \mathrm{~km}$ to $1.1 \cdot 10^{-4} \mathrm{sec}^{-1}$ at $22.5 \mathrm{~km}$. It is apparent that the dissociation of water vapor increases with height and, as a result, the hydrogen reactions are more important to equilibrium distribution of ozone density and temperature with increasing height.

In Figure 6 equilibrium temperature profiles are shown for the three different sets of rates for reactions (5) and (6) and for the two cooling rate coefficients, fast and slow. The water vapor mixing raiso used is $5 \cdot 10^{-6}$ while the low nixing ratio for nitrogen oxides is usec. The slow cooling rate coefficient $\left(a^{-1}=17\right.$ days) is $70 \%$ longer than the fast one $\left(\mathrm{a}^{-1}=10\right.$ days) above $35 \mathrm{~km}$. From eq (50) it might be expected that a $70 \%$ decrease in ' $a$ ' would lead to a $70 \%$ increase in $\left(T-180^{\circ}\right)$ rather than the $25 \%$ increase $($ at $45 \mathrm{~km}$ ) indicated in Figure 6 . Such is not the case, since the ozone density itself is strongly temperature dependent through reactions (5) and (6) and increasing the temperature decreases the ozone density and thus the absorption of energy. Therefore tire equilibrium temperature is buffered against change. An alteration in the cooling is nearly compensated for by a corresponding alteration in the heating so the fractional change in the equilibrium temperature is actually much smaller than the fractional changes in either the cooling or heating. 
Coupling of temperature and ozone density is obvious for an $O$ atmosphere (reglecting the hydrogen and nitrogen reactions) since

becomes

$$
O=C-A_{\varphi}^{2}
$$

and, from eqs (26) and (9)

$$
A=\frac{2\left(q_{3 a}+q_{3 b}\right) k_{6}}{{ }^{n_{O_{2}} k_{5}} .}
$$

In. which the ratio $k_{6} / k_{5}$ is strongly temperature dependent. It should be noted that for each set of rates for $k_{5}$ and $k_{6}$ in Table 2 , the ratio $\mathrm{k}_{6} / \mathrm{k}_{5}$ is strongly temperature dependent. In fact, the temperature denendence of $k_{0} / k_{5}$ for set 1 is exp $(-3395 / T)$ which is very close to that of exp $(-3295 / T)$ found for set 2 . The temperature dependence of set 3 is somewhat less and the effezt of this will be discussed in section 5 . When hydrogen reactions are dominant in detemining the : ozone density (as appears to be the case above $45 \mathrm{~km}$ for a water vapor -mixing ratio of $5 \cdot 10^{-6}$, it might appear that the temprature dependence of the ozone density would be greatly reduced, since the hydrogen reactions do not have rates that are strongly temperature dependent. Above $45 \mathrm{~km} \mathrm{eq} \mathrm{(49)} \mathrm{can} \mathrm{be} \mathrm{approximated,} \mathrm{by} \mathrm{use} \mathrm{of} \mathrm{eqs} \mathrm{(27)} \mathrm{and} \mathrm{(9),} \mathrm{as}$

$$
0=C-B \phi \psi
$$


where (above $45 \mathrm{~km}$ ),

$$
B \cong \frac{2\left(q_{3 a}+q_{3 b}\right) k_{9}}{n_{O_{2}} k_{5}}
$$

It is true that $k_{9}$ is not temperature dependent but $k_{5}$ is strongly temperature dependent. Therefore, the presence of hydrogen reactions does not climinate the buffering of the temperature profile. This result should be expected since the hydrogen reactions only destroy ozone while the production of ozone by reaction (5) is temperature dependent no matter what destruction processes are dominant. Eqs (55) and (56) indicate that the ozone density and, thus, temperature profile above $45 \mathrm{~km}$ are dependent on the rate used for reaction (5). The temperature profiles in Figure 6, where three different values are used for the rate of reaction (5), show this dependence. The mixing ratio of $\mathrm{OH}$ may be estimated from eq (50) as

$$
\psi=\left(\frac{D_{Q}+G}{E}\right)^{1 / 2}
$$

The use of eqs (30), (31), and (32) in (57) gives

$$
\psi=\left\{\frac{k_{8} q_{3 b}{ }^{/ k}{ }+q_{H_{2}}}{\left(k_{13}+R_{2} k_{14}\right) n_{m}}\right\}^{1 / 2}\left\{\frac{n_{2} O}{n_{m}}\right\}^{1 / 2} .
$$


Thus the mixlng ratio of $\mathrm{OH}$ is proportional to the square root of the water vapor mixing ratio. From eq (49) it is apparent that the importance of the hydrogen reactions to the ozone mixing ratio is directly proportional to $B \phi \psi$. Thus, increasing the water vapor mixing ratio both increases the importance of the hydrogen reactions at a given height and decreases the helght at which the hydrogen reactions become dominant in determining the ozone mixing ratio.

Above $45 \mathrm{~km}$ eq (13) may be.used for $\mathrm{R}_{2}$; i.e.,

$$
R_{2} \approx \frac{k_{9}}{k_{11}}\left(1+\frac{n_{0}{ }^{k_{27}}}{n_{0_{2} n^{k_{10}}}}\right)^{-1}
$$

and (58) becomes

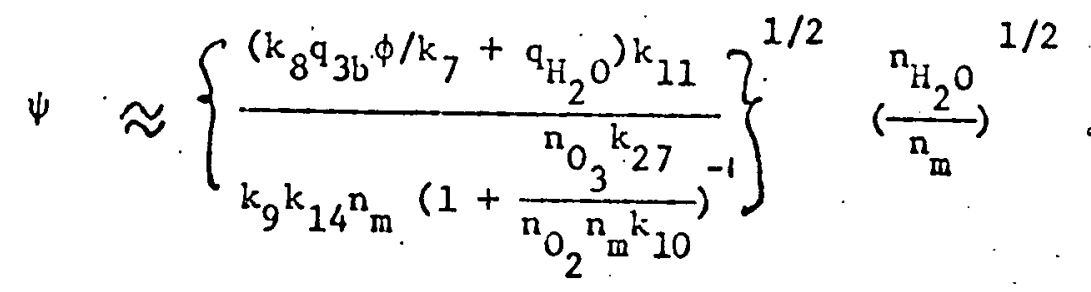

Also, above $45 \mathrm{~km}$, we may use an approximate form of (33); 1.e.,

$$
B \approx 2 R_{1} k_{9} n_{m}
$$

Eqs (59), (60), and (61) are not used in our radiative photochem-. ical equilibrium calculations but they are useful in cstimating the effect of varying the rates for the hydrogen reactions. 
It is apparent from eq $(60)$ that changes in $k_{8}, k_{11}, k_{9}, k_{14}, k_{27}$, and $k_{10}$ will be undistinguishable in their effects from changes in the assumed water vapor mixing ratio. The effect of varying the water vapor mixing ratio has been discussed previously. We shall return to this matter later in evaluating our quantitative results.

The effect of the nitrogen reactions on the ozone mixing ratio is indicated in eq (49) by - FфX. Use of eqs (28), (14), and (21) plus the fact that $R_{1} k_{16}>k_{18}$ at ail heights yields

$$
F_{\varphi} x \approx \frac{2 R_{1} k_{16}{ }^{n} \mathrm{~K}_{\varphi}}{1+R_{3}} \quad \ldots \quad \ldots
$$

Using eq (14) we estimate that $R_{3}<1$ below $35 \mathrm{~km}$ and $R_{3} \approx$ $\mathrm{R}_{1} \mathrm{k}_{16} / \mathrm{k}_{17}$ above $35 \mathrm{~km}$ so

$$
\mathrm{F}_{\varphi} \mathrm{X} \approx 2 \mathrm{R}_{1} \mathrm{k}_{16} \mathrm{n}_{\mathrm{m}} \mathrm{K}_{\varphi} \text { below } 35 \mathrm{~km}
$$

and

$$
\mathrm{F}_{\varphi} \mathrm{X} \approx 2 \mathrm{R}_{1} \mathrm{k}_{16}{ }^{\mathrm{n}} \mathrm{K}_{\varphi} /\left(1+\mathrm{R}_{1} \mathrm{k}_{16} / \mathrm{k}_{17}\right) \text { above } 35 \mathrm{~km}
$$

It is apparent from eqs (63) and (64) that variations in $k_{16}$ or $k_{17}$ may be equivalently expressed as changes in $\mathrm{K}$, the mixing ratio of nitrogen oxides. The effect on the ozone mixing ratio due to varying the nitrogen oxides mixing ratio has already been indicated. 
- Finally, it should be noted that below $30 \mathrm{~km}$ the photochernical time scale fur: ozone is so long (several works to years) that dynamical effects can be significant. It follows that joint radiative-photochemical equilibrium calculations should not be expected to give results in agreement with observed temperature and ozone density distributions. Above $35 \mathrm{~km}$ both the photochemical time scale $(<1$ day) and the radiative-photochemical cooling time scale (about a few days) are short enough that dynamical effects are unimportant. Therefore equilibrium calculations should give appropriate values of ozone density and temperature.

Figures $2-6$ clearly show that distributions of ozone temperature and density depend on values used for parameters such as reaction rates, cooling time scale, and mixing ratios of water vapor and nitrogen oxides. These parameters can be adjusted to yield distributions which best match the observed distributions of ozone density and temperature. Comparison of ozone measurements made by several investigators (Johnson et a1. 1954, Rawcliffe et al. 1963, illler and Stewart 1965, Weeks and Solth 1968, Hilsenrath et al. 1969) shows a range in number density as large as an order of magnitude at some heights in the $35-61 \mathrm{~km}$ region. Since the temperature in this region is much better determined as in the U.S. Standard Atmosphere 1962 or Supplemental Atmospheres (Handbook of Geophysics and Space Environments), temperature rather than 
ozone density is used to determine the match of the equilibrium calcilations to observations. However, as we shall sce, a rather systematic. difference between our predicted ozone distribution and those observed. may indicate an error in our cholce of cooling rate cocfficient.

The Supplemental Atmosphere (Tropical) has a stratopause temperature of $270^{\circ} \mathrm{K}$ with $243^{\circ} \mathrm{K}$ at $35 \mathrm{~km}$ and $250^{\circ} \mathrm{K}$ at $61 \mathrm{~km}$. In Figures 2, 4, and 6 all stratopause temperatures are higher than $270^{\circ} \mathrm{K}$. Of the three sets of reaction rates for the pure oxygen reactions, set 1 gives the smallest st ratopause temperature. Also, from Figure 6 the fast cooling rate $\left(a=(10 \text { days })^{-1}\right.$ above $\left.35 \mathrm{~km}\right)$ always gives lower stratopause temperatures than the slow cooling rate $\left(a=(17 \text { days })^{-1}\right)$. Set 1 for the pure oxygen reaction ::ates and the fast cooling rate are used in the calculations to model the temperature. This choice means smaller mixing ratios of water vapor and nitrogen oxides are needed to lower the calculated stratopause temperature to that of the Supplemental Atmosphere (Tropical) than if a slower cooling rate or another set of rates for the pure oxygen reactions were used.

Temperature profiles in Figures 2 and 4 indicate that cases with water vapor absent have a nearly constant temperature above the stratopause while cases with a water väpor mixing ratio of $5 \cdot 10^{-6}$ show a decrease of $55-75^{\circ} \mathrm{K}$ in temperature from the stratopause to $61 \mathrm{~km}$. Since the Supplemental Atmosphere (Tropical) has a $20^{\circ} \mathrm{K}$ decrease from 
the stratopause to $61 \mathrm{~km}$, the water vapor mixing ratio is between $z$ ere and $5 \cdot 10^{-6}$. A value of $5 \cdot 10^{-7}$ gives $\sim 23^{\circ} \mathrm{K}$ decrease between the stratopause and $61 \mathrm{~km}$ but is less than the $2-6 \cdot 10^{-6}$ value for the water vapor mixing ratio that measurements indicate (Mastenbrook 1968, Schöz et al. 1970). As eqs (60) and (61). indicate a decrease in the dissociation rates of water vapor, a decrease in $k_{11}$ or $k_{9}$, or an increase in $k_{14}$ would mean the water vapor mixing ratio must be increased to maintain the same calculated equilibrium temperature profile.

The effect of various nitrogen oxide mixing ratios on the stratopause temperature is shown in Table 3. Profiles 1 and 2 axe the low and high nitric oxide mixing ratios described previously. Profiles 3 , 4, and 5 have constant nitrogen oxides mixing ratios of $\mathrm{K}=3 \cdot 10^{-9}$, $3 \cdot 10^{-8}$, and $1 \cdot 10^{-7}$, respectively, Profile 6 has

$$
\begin{array}{ll}
K=3 \cdot 10^{-9} & z<35 \mathrm{~km} \\
K=3 \cdot 10^{-9} \exp \left(\frac{z-35}{6}\right) \cdot 35 \mathrm{~km}<z<45 \mathrm{~km} \\
K=1.6 \cdot 10^{-8} & z>45 \mathrm{~km} .
\end{array}
$$

Profile 7 is simply Profile 6 with the $K$ values multiplied by 10 . Profile 8 has no nitrogen oxides included. Profiles 2, 5, and 7 yield about the same stratopause temperature. Profile 5 with a constant mixing ratio is unsuitable since the temperature decreases by $56^{\circ} \mathrm{K}$ from tine 
stratopause down to $35 \mathrm{~km}$ as opposed to a $27^{\circ} \mathrm{K}$ decrease in the Supplemental Atmosphere (Tropical). Profile 2 has a mixing ratio of nitroge: oxides which continues to increase with height above $45 \mathrm{~km}$. Consequently the temperature decrease from the stratopause to $61 \mathrm{~km}$ is $31^{\circ} \mathrm{K}$ for Profile 2 as opposed to $23^{\circ} \mathrm{K}$ for Profile 7 which has a constant nitrogen oxides mixing ratio above $45 \mathrm{~km}$. Therefore Profile 7 is preferred of those tried. The mixing ratio of nitrogen oxides at a given height affects the calculations at lower heights only if the amount of solar energy reaching the lower heights depends on the nitrogen oxides mixing ratio higher up. This dependence occurs if the nitrogen oxides are strong absorbers of solar energy or if the nitrogen reactions strongly alter the ozone density since ozone is a strong absorber of solar energy in the relevant frequency intervals. The former is not true and above $50 \mathrm{~km}$, for the mixing ratios of nitrogen oxides used here, neither is the latter. Thus, equilibrium distributions found at the stratopause depend only on the nitrogen oxides mixing ratio at that height. From Table 3; we conclude that, since Profiles 2, 5, and 7 all give stratopaluse temperatures of about the same size, that a mixing ratio for nitrogen oxides in the range of $8-16 \cdot 10^{-8}$ is acceptable for the reaction and cooling rates used. ilowever, as will be seen in section 6a, our choice of cooling rate may be too low in which case we are requiring that ozone density be too low and consequently exaggerating the need for ozone loss processes. A larger value of ' $a$ ' will much dimintsh our need for ${ }^{*}$. Horeover, we are really specifying $F X$ in 
(40) rather than the No $x$ ixing ratio, and changes in reaction rates would alter our estimate for the latter.

From eq (64) it is apparent that the mixing ratio of nitrogen oxides needed to give a particular temperature distribution is altered when the reaction rates, $k_{16}$ and $k_{17}$, are altered.

The treatment of the day-night differences in photochemistry is fairly crude. However, time-dependent $\ddot{c}$ alculations have been made for the daily variations in ozone density and temperature for Profiles 7 and 8. The temperatures at the stratopause, averaged over 24 hours, are listed in Table 3. The stratopause temperature from the timedependent calculations is $15^{\circ}-17^{\circ} \mathrm{K}$. lower than that found in the joint radiative-photochemical equilibrium calculations. For Profile 7 the resulting stratopause temperature of $273^{\circ} \mathrm{K}$ is in good agreement with the $270^{\circ} \mathrm{K}$ stratopause temperature of the Supplemental Atmos phe re (Tropical). The results of the time-dependent calcuiations will be reported separately.

The $15^{\circ} \mathrm{K}$ difference between stratopause temperature found for radiative-photochemical equilibrium calculations and for the timedependent calculations when the same reaction rates and mixing ratios of water vapor and nitrogen oxides are used is due to the crude averaging technique for day-night differences in the radiative-photochemical calculations. As discussed earlier in this section solar encray absorption occurs on ly during daylight lours. The average energy absorption 
rate was set equal to half of the noontime energy absorption ratc. It was pointed out that this treatment of day-night differences leads to an overestimate in the energy absorption rate and, consequently, an overestimate in the radiative-photochemical temperature. From eqs (49), $(50),(51),(55)$; and (56) it is seen that a stratopause temperature of $273^{\circ} \mathrm{K}$ instead of $283^{\circ} \mathrm{K}$ results when (all other parameters being the same) the noontime energy absorption divided by $2: 4$.instead of 2 is . used for the average energy absorption rate.

\section{4a. CRITICAL ASSESSIIENT OF EOQUILIBRIUR RESULTS}

The above results wille interesting are not as important as the fact that the system we have developed is simple enough to permit the inmediate evaluation of the effects of various changes and the ilentification of questionable rate coefficients. In this section we will use this simplicity in order to assess and extend the results obtained above.

In the above scheme we have essentially asked what anount of ozone is necessary to produce the observed mean temperature between $35 \mathrm{~km}$ and $60 \mathrm{~km}$. The amount is less than what one would obtain from simple oxygen chemistry. So we further inquired how much $\mathrm{H}_{2} \mathrm{O}$ and $\mathrm{NO}_{x}$ would be needed for the various catalytic destructions of ozone to reduce the value to that needed. For the reaction and cooling rate coefficients used we obtained answers. to these questions, and these answers seem questionable on at least threc counts:

1) The density of ozone calculated between 40 and $50 \mathrm{~km}$ is about $30 \%$ less than the few existing measurements indicate; 
i1) The suggested mixing ratio for $\mathrm{NO}_{\mathrm{x}}$ at $50 \mathrm{~km}, 1.6 \cdot 10^{-7}$, is ligher than has hitherto been suggested; and

ii1) The mixing ratio for $\mathrm{H}_{2} \mathrm{O}$ suggested, $5 \cdot 10^{-7}$, is less than currently believed.

For argument's sake, let us assume the above discrepancies are are real, and attempt to track down their origins. Item (i) is entirely determined by eq (5I); i.e., it is independent of any chemical assumptions, and depends only on our choice of solar intensity and absorption cross-sections in ozone's absorption bands and on our choice of ' $a$ ', the cooling rate coefficient. Considerable uncertainty exists concerning the value of ' $a$ ' at $50 \mathrm{~km}$. If it were $30 \%$ 1arger, $30 \%$ more ozone would be needed to produce the observed $\bar{T}$. Dickinson (1972, private communication) has informed us that his current calculations of $15 \mu \mathrm{CO}_{2}$ cooling suggest that ' $\mathrm{a}$ ' indeed continues to increase above $35 \mathrm{~km}$ to values on the order of $30 \%$ higher than $1 / 10$ days above $40 \mathrm{~km}$.

W1th $30 \%$ more ozone above $40 \mathrm{~km}$, the loss terms due to hydrogen and nitrogen reactions must be reduced. Assuming our reaction rates are correct, this can be achieved by reducing our mixing ratios for No $_{x}$ and $\mathrm{H}_{2} \mathrm{O}$. We rule out the latter on two counts:

a) Our value for $n_{\mathrm{H}_{2} \mathrm{O}} / \mathrm{n}_{\mathrm{m}}$ already seems low (viz item 3), and, more important,

b) The value we have chosen for $n_{H_{2}} \mathrm{O}^{/ n_{m}}$ determines not only the value of $\phi$ (and hence temperature) at $50 \mathrm{~km} \cdot b u t$ also the gradient of terperature above $50 \mathrm{~km}$ where ${ }^{2}{ }_{\mathrm{x}}$ has a neglisible effect. 
We are, therefore, forced to reduce our infxing ratio for $\mathrm{NO}_{\mathrm{x}}$. To a flow for $30 \%$ more ozone, this mixing ratio must be decreased from $1.6 \cdot 10^{-7}$ to about $2.4 \cdot 10^{-8}$. The latter value seens more plausible (viz 1 ted ( $i$ )) and in turn supports the cirolce of the larger value for 'a'. Thus, a plausible cholce for the $\mathrm{NO}_{\mathrm{x}}$ mixing ratto between 35 and $50 \mathrm{~km}$ appears to be $2-3 \cdot 10^{-8}$. This is considerably more (by about a factor of 20) than what is expected will be produced by full scale SST operations (Johnston, 1972). Thus, while SST effects should be discernible, they snould not be catastrophic. In particular, a change of $5 \%$ in $\mathrm{NO}_{\mathrm{x}}$ should not produce a similar change in $\phi$ since nitrogen reactions ire not the only loss processes for ozone and also because of the themin buffering already described. Tuming, finally, to iten (iii) we must note that the quantity we have chosen is not really $\mathrm{n}_{\mathrm{H}_{2} \mathrm{O}} / \mathrm{n}_{\mathrm{m}}$ but $\mathrm{B} \psi$ in eq (49). From eqs (60) and (61) we have that

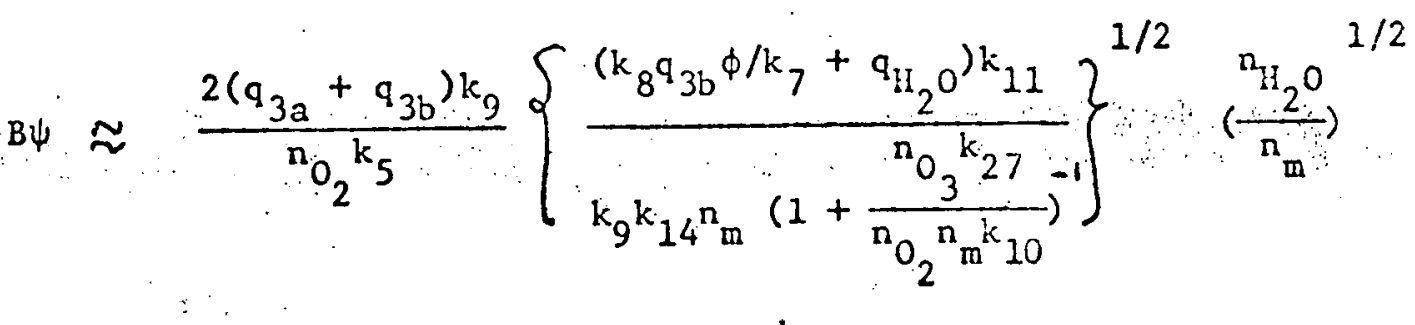

above $45 \mathrm{~km}$.

clearly, various changes in reaction rate coefficients could allow a greater value for $\left(\frac{\mathrm{n}_{2} \mathrm{O}}{\mathrm{n}_{\mathrm{n}}}\right)$ without changing $B \psi$. Recent measurements brought to our attention by $S$. Wofsy suggest our rate for $k_{g}$ should be increased from $5 \cdot 10^{-11}$ to $2 \cdot 10^{-10}$ while $k_{14}$ should be changed from 
$10^{-11}$ to $2 \cdot 10^{-10}$ (see Wofsy et al. 1972 for references). With these new rates $\frac{n_{H_{2}} O}{n_{m}}$ must be increased to about $3 \cdot 20^{-6}$ to maintain a given value for Bi,. Discrepancy (i1i) argues in favor of the new rates. 


\section{RELAXATION TIME SCALES}

Suppose we consider small perturbations from the radiativephotochemical equilibrium state calculated in section 4. Then linearization of eqs (22), (23), and (45) yiclds the equations which can be solved for the time scales for return to radiative-photochemical eciulibrium. The equations are, with winds neglected,

$$
\begin{aligned}
& \frac{\partial Q^{\prime}}{\partial t}=-\mathcal{B} \varphi^{\prime} \therefore C \psi^{\prime}-\not \mathcal{H} T^{\prime}, \\
& \frac{\partial \psi^{\prime}}{\partial t}=D \varphi-\varepsilon \psi^{\prime}-I T^{\prime}, \\
& \frac{\partial T^{\prime}}{\partial t}=n \varphi^{\prime}-a T^{\prime}
\end{aligned}
$$

where, using primes for perturbation quantities and overbars for

$\circ$ equilibrium value,

$$
\begin{aligned}
& \varphi=\bar{\varphi}+\varphi^{\prime} \\
& \psi=\bar{\psi}+\psi^{\prime} \\
& \mathrm{T}=\overline{\mathrm{T}}+\mathrm{T}^{\prime} \\
& \frac{\mathrm{n}}{\mathrm{m}_{\mathrm{m}}^{\prime}} \approx-\frac{\mathrm{T}^{\prime}}{\overline{\mathrm{T}}} \text { (valid for small pressure perturbations) }
\end{aligned}
$$




$$
\begin{aligned}
& \hat{B}=\left[2 \bar{A}_{\varphi}+\bar{B} \bar{\psi}\left(1+\delta_{1}\right)+\bar{F} \bar{X}\left(1+c_{1}\right)\right] /\left(1+R_{1}\right) \text {, } \\
& C=\bar{B} \bar{\varphi} /\left(I+R_{1}\right) \text {, } \\
& \mathcal{I}=\frac{\bar{\varphi}}{\mathrm{T}}\left[\alpha \overline{\mathrm{A}} \bar{\varphi}+\left(\beta-\delta_{2} \varepsilon_{2}\right) \overline{\mathrm{B}} \bar{\psi}+\left(f+\varepsilon_{2}\right) \overline{\mathrm{F}} \bar{X}\right] /\left(1+R_{1}\right) \text {, } \\
& \mathcal{D}=\left[\bar{D}-\& \bar{E} \bar{\psi}^{2} / \bar{\varphi}\right] /\left(1+R_{2}\right) \\
& \varepsilon=2 \bar{E} \bar{\psi} /\left(1+R_{2}\right) \text {, }
\end{aligned}
$$

and

$$
\exists=\left[r \overline{\mathrm{I}} \bar{\psi}^{2} / \bar{T}\right] /\left(1+R_{2}\right) .
$$

Further definitions are

$$
\begin{aligned}
& \alpha=1+\mathrm{e}_{6}-\mathrm{e}_{5} \\
& \gamma_{4}=\gamma_{1}+\gamma_{2}, \\
& \gamma_{1}=\frac{k_{16} k_{15}}{k_{17} \bar{\varphi}} \bar{x} /\left[k_{11}+\frac{R_{3} \bar{x} k_{15}}{R_{1} \bar{\varphi}}\right] \\
& \left.\gamma_{2}=\frac{k_{15} \bar{X} q_{N_{2}}}{R_{1} \bar{\varphi}^{2-n_{m} k_{17}} /\left[k_{11}\right.}+\frac{R_{3} \bar{X} k_{15}}{R_{1} \bar{\varphi}}\right] \\
& \omega=\frac{k_{12}}{k_{12}+R_{1} k_{9}}\left[e_{12}-\left(2-e_{5}\right)\right]-\gamma_{1}\left(e_{15}+e_{16}-e_{17}\right)
\end{aligned}
$$

$$
-\gamma_{2}\left[e_{15}+1-e_{17}-\left(2-e_{5}\right)\right] .
$$




$$
\begin{aligned}
& \varepsilon_{1}=q_{\mathrm{NO}_{2}} /\left[\left(\dot{1}+\mathrm{R}_{3}\right)\left(\dot{\varphi}_{\varphi_{\mathrm{m}}}^{-} \mathrm{k}_{17}\right)\right] \\
& \epsilon_{2}=-\frac{R_{1} k_{16}}{\left(1+R_{3}\right) k_{17}}\left[e_{16}+\left(2-e_{5}\right)-e_{17}\right]-\varepsilon_{1}\left(1-e_{17}\right) \text {, } \\
& \varepsilon=r_{3} \quad z \leq 40 \mathrm{~km} \\
& g=-\Delta /(1+\Delta)^{2} \cdot \frac{k_{9}}{k_{11}} \frac{1}{R_{2}} \quad z \geq 40 \mathrm{~km} \\
& \Delta=\bar{\phi} \frac{\mathrm{k}_{27}}{\mathrm{n}_{\mathrm{O}_{2}} \mathrm{k}_{10}} \\
& \gamma_{3}=\gamma_{4}\left(1+\varepsilon_{1} / R_{3}\right) \\
& r=\omega-\varepsilon_{2} \gamma_{4}-1 \quad z \leq 40 \mathrm{~km} \\
& =\frac{-\Delta}{(1+\Delta)^{2}} \cdot \frac{k_{9}}{k_{11} R_{2}}\left(e_{2 i}+1\right)+\frac{k_{12}}{R_{1} k_{11} R_{2}}\left(e_{12}-2+e_{5}\right)-i \\
& z \geq 40 \mathrm{~km} \\
& f=-1+\left[2 R_{1} k_{16}\left(e_{16}+2-e_{5}\right)+k_{18} e_{18}\right] /\left[2 R_{1} k_{16}+k_{18}\right] \\
& \beta=-1+\left[\left(k_{9}+R_{2} k_{11}\right)\left(2-e_{5}\right) R_{1}+R_{1} R_{2} R_{11} u\right. \\
& \left.+k_{12} e_{12}\right] n_{m} / \bar{B}
\end{aligned}
$$




$$
\delta_{1}=Y_{3} R_{1} R_{2} k_{11}{ }^{n} m / \bar{B}
$$

$$
\delta_{2}=\delta_{1} \gamma_{4} / \gamma_{3}
$$

$$
e_{i}=\frac{\bar{T}}{k_{i}}\left(\frac{d k_{i}}{d T}\right) \quad(i=5,18),
$$

and, from the linearization of eq (24),

$$
\frac{X^{\prime}}{\bar{x}}=\epsilon_{1} \frac{\varphi^{\prime}}{\varphi}+\epsilon_{2} \frac{T^{\prime}}{\bar{T}}
$$

The complexity of our coefficients in (65) and (66) arises hecalise some of the reaction rates, $k_{i}$, and the ratios $R_{1}, R_{2}$, and $R_{3}$ are terperature dependent and the ratios $R_{2}$ and $R_{3}$ are also dependent on the ozone mixing ratio. There are additional terms in ens (65) and (66) which have been neglected since they are much smaller than those retained. If there is no coupling, then the time scale for return to equilibrium is $B^{-1}$ for the ozone mixing ratio, $\mathcal{E}^{-1}$ for the hydroxy 1 mixing ratio, and $\mathrm{a}^{-1}$ for the temperature. The terms $C \psi^{\prime}, \mathbb{A}^{\prime} \mathrm{T}^{\prime}, \mathscr{Q}_{\phi^{\prime}}$, $F^{\prime} T^{\prime}$, and $n \phi^{\prime}$, represent the coupling between the photochemical and radiative processes. 
Eqs (65), (66), and (67) may be combined to:

where

$$
\left[\frac{\partial 3}{\partial t^{3}}+M \frac{\partial^{2}}{\partial t^{2}}+N \frac{\partial}{\partial t}+S\right]\left\{\begin{array}{c}
\varphi^{\prime} \\
\psi^{\prime} \\
T^{\prime}
\end{array}\right\}=0 .
$$

$$
\begin{aligned}
& M=a+B+\varepsilon \\
& N=B \varepsilon+a \beta+\varepsilon a+\mu_{\eta}+c D \\
& s=\varepsilon a B+\eta J \varepsilon+C a D-z c_{\eta} .
\end{aligned}
$$

Initial conditions are needed to solve eq (74) and we consider three cases:

(1) $\varphi^{\prime}(t=0)=\varphi(0)$,

$$
\begin{aligned}
\psi^{\prime}(t=0) & =0, \\
T^{\prime}(t=0) & =0, \\
\varphi^{\prime}(t=0) & =0, \\
\psi^{\prime}(t=0) & =\psi(0), \\
T^{\prime}(t=0) & =0,
\end{aligned}
$$

and

(3) $\varphi^{\prime}(t=0)=0$,

$$
\begin{aligned}
& \psi^{\prime}(t=0)=0 \\
& T^{\prime}(t=0)=T(0) .
\end{aligned}
$$

The solution for $\varphi^{\prime}$ for case 1 is

$$
\varphi^{\prime}=\varphi(0) K_{11} e^{\sigma_{1} t}+K_{21} e^{\sigma_{2} t}+K_{31} e^{\sigma_{3} t} ;
$$


the solution for $\psi^{\prime}$ for case 2 is

$$
\psi^{\prime}=\psi(0) K_{12} \mathrm{e}^{\sigma_{1} t}+\mathrm{K}_{22} \mathrm{e}^{\sigma_{2} t}+\mathrm{K}_{32} \mathrm{e}^{\sigma_{3} t} .
$$

and the solution for $T^{\prime}$ for case 3 is

$$
T^{\prime}=T(0) K_{13} e^{\sigma_{1} t}+K_{23} e^{\sigma_{3} t}+K_{33} e^{\sigma_{3} t}
$$

The coefficients are defined as

$$
\begin{aligned}
& K_{1 j}=\left(\theta_{j}+V_{j}\left(\sigma_{2}+\sigma_{3}\right)+\sigma_{2} \sigma_{3}\right) /\left[\left(\sigma_{1}-\sigma_{3}\right)\left(\sigma_{1}-\sigma_{2}\right)\right] ; \\
& K_{2 j}=\left(\theta_{j}+V_{j}\left(\sigma_{3}+\sigma_{1}\right)+\sigma_{1} \sigma_{3}\right) /\left[\left(\sigma_{2}-\sigma_{3}\right)\left(\sigma_{2}-\sigma_{1}\right)\right] ; \\
& K_{3 j}=\left(\theta_{j}+V_{j}\left(\sigma_{1}+\sigma_{2}\right)+\sigma_{1} \sigma_{2}\right) /\left[\left(\sigma_{3}-\sigma_{1}\right)\left(\sigma_{3}-\sigma_{2}\right)\right]
\end{aligned}
$$

where $j=1,2,3$ and

$$
\begin{aligned}
& v_{1}=\beta, \\
& v_{2}=\varepsilon . \\
& v_{3}=a . \\
& \theta_{1}=B^{2}-\eta \dot{B}-c D, \\
& \theta_{2}=\varepsilon^{2}-C \theta, \\
& \left.\theta_{3}=a^{2}-\eta\right) .
\end{aligned}
$$

The values $\sigma_{1}, \sigma_{2}$, and $\sigma_{3}$ are roots of the cubic equation:

$$
\sigma_{3}+1 \cdot \sigma^{2}+\mathrm{No}+S=0
$$

which follows from eq (74). 
For cases where the hydrogen reactions are neglected (74) reciuces to:

$$
\left[\frac{\theta^{2}}{t^{2}}+(a+B) \frac{\lambda}{\partial t}+\left(a \mathcal{B}+J_{n}\right)\right]\left(\frac{0^{\prime}}{T^{\prime}}\right)=0
$$

with the solution for $\varphi^{\prime}($ case 1$)$ as

$$
\varphi^{\prime}=\varphi(0) \frac{\hat{\sigma}_{2}+\hat{B}}{\hat{\sigma}_{2}-\hat{\sigma}_{1}} \mathrm{e}^{\hat{\sigma}_{1} t} \cdot \frac{\hat{\sigma}_{1}+\hat{B}}{\hat{\sigma}_{2}-\hat{\sigma}_{1}} \hat{\sigma}_{2}^{t}
$$

and the solution for $T^{\prime}$ (case 3 ) as

$$
T^{\prime}=T(0) \frac{\hat{\sigma}_{2}+\alpha}{\hat{\sigma}_{2}-\hat{\sigma}_{1}} e^{\hat{\sigma}_{1} t}-\frac{\hat{\sigma}_{1}+\alpha}{\hat{\sigma}_{2}-\hat{\sigma}_{1}} e^{\hat{\sigma}_{2} t} .
$$

where

$$
\begin{aligned}
& \hat{\sigma}_{1}=\frac{1}{2}-(\alpha+\mathcal{B})-\left[(\alpha-\not B)^{2}-4 \eta \mathcal{J}\right]^{1 / 2} \\
& \hat{\sigma}_{2}=\frac{1}{2}-(a+\mathcal{B})+\left[(a-B)^{2}-4 \eta \mathcal{J}\right]^{1 / 2} .
\end{aligned}
$$

In Figure 7 time scales $a^{-1}, B^{-1}, \tau_{1}\left(=-\left(\operatorname{Re} \hat{\sigma}_{1}\right)^{-1}\right)$, and $\tau_{2}\left(=-\left(\operatorname{Re} \hat{\sigma}_{2}\right)^{-1}\right)$ are plotted for the pure $O$ case with set 1 for rates of reactions (5) and (6) and the fast profile of a. The possibility of complex $\hat{c}_{1}$ and $\hat{\sigma}_{2}$ merely means that the coupling results in an oscillating decay of the 
perturbations. The time scale $B^{-1}$ is several years at $22 \mathrm{~km}$ ard decreases to dbout 90 minutes at $50 \mathrm{~km}$ aris then increases above to about $1 / 10$ day at $61 \mathrm{~km}$. When coupling is included the actual time scale for thermal relaxation $i s \tau_{1}$ and for ozone relaxation is $\tau_{2}$. As shown in Figure 7 coupling results in à slightly morc rapid ozone relaxation below $30 \mathrm{~km}$ and a slightly slower ozone relaxation above $30 \mathrm{~km}$. Below $30 \mathrm{~km}$ coupling causes a slower thermal relaxation. If we write eqs (79) and (80) as

$$
\begin{aligned}
& \hat{\sigma}_{1}=-\frac{(a+\hat{B})}{2}-\delta / 2 \\
& \hat{\sigma}_{2}=\frac{-(a+\mathcal{B})}{2}-\delta / 2
\end{aligned}
$$

. where $\delta \equiv\left[(a-\mathcal{B})^{2}-4 \not{J} \eta\right]^{1 / 2}$ and then substitute eqs (81) and (82) into eq (78), the result is

$$
\begin{aligned}
T^{\prime} & =\frac{T(0)}{2 \delta} e^{-\frac{(a+\mathcal{B})}{2} t} \cdot\left[( \mathcal { B } - a ) \left(\mathrm{e}^{\delta / 2 t}-\mathrm{e}^{-\delta / 2 t}\right.\right. \\
& \left.+\delta\left(\mathrm{e}^{\delta / 2 t}+\mathrm{e}^{-\delta / 2 t}\right)\right]
\end{aligned}
$$


Now $\delta / 2<(a+\mathcal{B}) / 2$ and if wo consider an expansion of $e^{ \pm \delta / 2 t}$ for time $\left\langle(\delta / 2)^{-1}\right.$ the : we may write eq (83) as

$$
T^{\prime} \approx T(0) e^{-\frac{(a+\mathcal{B})_{t}}{2}}\left[1-\frac{(a-\mathcal{B})}{2} t\right]
$$

or

$$
T^{\prime} \approx T(0) e^{-\alpha t}
$$

Thus, if we are considering a wave with period $\tau<a^{-1}$, then the actual time scale for thermal relaxation is not $\tau_{1}$ but $a^{-1}$ below $30 \mathrm{~km}$ where eqs (84) and (85) are good approximations to eq (83). .

Above $30 \mathrm{~km}^{-1}$ is much less than $a^{-1}$, and coupling between the photochemical and radiative processes results in more rapid theiral relaxation as show $\mathrm{n}$ in Figure 7. Lindzen and Goody (1965) also found. that thermal relaxation was more rapid above $30 \mathrm{~km}$, though they . used a different set of rates for reactions (5) and (6).

$$
\text { Above } 40 \mathrm{~km}, 4(y)+a \dot{B})\left\langle(a+B)^{2} \text { and } \mathcal{B}^{-1}<\left(a^{-1}\right. \text { so eq }\right.
$$
(81) can be approximated:

$$
\hat{\sigma}_{1} \approx-\frac{M n}{B}
$$

For the pure $O$ case eqs $(68)$ and $(70)$ reduce to

$$
\begin{aligned}
& B=2 A_{\varphi} \\
& Y=2 \bar{A} \bar{\varphi}_{\bar{T}}^{\bar{T}}
\end{aligned}
$$


Use of eqs (87) and (88) in eq (86) yiclds :-

$$
\hat{\sigma}_{1} \approx-\frac{\operatorname{cs} \overline{A_{\alpha} \bar{\alpha}} / \overline{\mathrm{T}}}{2 \overline{\mathrm{A}_{\varphi}}}=-\frac{\alpha \bar{n}_{0}}{2 \overline{\mathrm{T}}}
$$

Substitution of eq (51) 1nto eq (89) gives

$$
\hat{\sigma}_{1} \approx-\frac{\alpha \alpha}{2}\left(1-\frac{180^{\circ}}{\bar{T}}\right) .
$$

From Figures 2 and 4 we see that the equilibrium temperature for the pure $O$ case is nearly constant above $40 \mathrm{~km}$ so, from eq (90)

$\hat{o}_{1} \approx$ constant above $40 \mathrm{~km}$

as. is shown in Figure 7.

The $\mathrm{N}+\mathrm{H}+\mathrm{O}$ case requires the solution of eq (75). In Figure 8 axe plotted the values $Q^{-1}, B^{-1}$, and $E^{-1}$ as well as $\tau_{1}, \tau_{2}$, and $\tau_{3}\left(=-\left[\mathrm{ReC}_{3}\right]^{-1}\right)$, where $\tau_{3}$ is the hydroxyl relaxation time scale when coupling is included. Set 1 is used for rates for reactions (5) and (6) and the fast profile is used for $a$. The water vapor mixing ratio is $5 \cdot 10^{-6}$ while the low mixing ratio profile for the nitrogen oxides is used. In Figure 8 we see that below $40 \mathrm{~km} \tau_{3} \approx \varepsilon^{-1}$ and $\tau_{1}$ and $\tau_{2}$ are approximately the same as for the pure $O$ case. This result is reasonable since 
we previously found that inclusion of the hydrogen reactions has litile effect on the equilibrium distribution of imperature and ozone density below $40 \mathrm{~km}$. The only effect of the nitrogen reactions is to shorten $B^{-1}$ at the lowest altitudes.

Above $40 \mathrm{~km}$ the hydrogen reactions become increasingly important with $\varepsilon^{-1}$ nearly the same size as $B^{-1}$. The time scale for relaxation of a perturbation in the ozone density or hydroxyl density is modified since there is strong coupling between the ozone and hydrogen photocheristry. The photochemical acceleration of the thermal relaxation is modified but not eliminated. Above $40 \mathrm{~km}$ eq (86) is applicable and:

$$
\sigma_{1} \approx-S_{n} / 0 \text {. }
$$

For the $\mathrm{N}+\mathrm{H}+\mathrm{O}$ case above $40 \mathrm{~km}$ eqs $(68)$ and $(70)$ reduce to:

$$
\begin{aligned}
& B \approx B \psi \\
& J \approx \beta B \bar{\psi} / \bar{T}
\end{aligned}
$$

so substitution of eqs (92), (93), and (53) into eq (91) yields

$$
\sigma_{1} \approx \beta_{n \bar{\varphi}} / \overline{\mathrm{T}}=\beta a\left(1-\frac{180^{\circ}}{\overline{\mathrm{T}}}\right)
$$

Now the equilibrium temperature for the $\mathrm{N}-\mathrm{H}-\mathrm{O}$ cașe in Figures 2 and 4 decreases nearly lincarly above $42 \mathrm{~km}$ and this decrease is reflected in the nearly linear. increase of $\tau_{1}$ with height in Figure 8. 
Figure 9 shows $\tau_{1}$ for six cases: $\mathrm{O}, \mathrm{H}+\mathrm{O}, \mathrm{N}+\mathrm{O}$ (low), $\mathrm{N}+\mathrm{O}$ (high), $\mathrm{N}+\mathrm{H} \div \mathrm{O}$ (low), and $\mathrm{N}+\mathrm{H}+\mathrm{O}$ (hisis). It is apparent that inclusion of nitrogen reactions for the low mixing ratio of nitrogen oxides does not alter $\tau_{1}$ from cases with no nitrogen present but use of the hidh mixing ratio increases $\tau_{1}$. The reason for this effect can be seen most readily by referring to the equilibrium eqs $(49),(50)$, and (51). The effect of nitrogen reactions on ozone density is contained in the term - FQX and above $35 \mathrm{~km}$ this term can be written, by application of eqs (29), (14), and (9), as:

$$
\mathrm{F}_{\varphi \mathrm{X}} \approx 2 \mathrm{k}_{17} \mathrm{~K}_{\varphi \mathrm{n}}
$$

The effect of the purc oxygen reactions on ozone density is contained in the term, $-\mathrm{A}_{\varphi}^{2}$ and from eqs (26) and (9), we have

$$
\therefore \quad A_{\varphi}^{2}=\frac{2\left(q_{3 a}+q_{3 b}\right)}{n_{O_{2}}}\left(k_{6} / k_{5}\right) \varphi^{2}
$$

Comparing the terms (95) and (96), we see that temperature dependence of ozone density due to nitrogen reactions is by $k_{17}$ and the temperature dependence of ozone density due the oxygen reactions is by $\left(k_{6} / k_{5}\right)^{1 / 2}$. The temperature dependence of $k_{17}$ is much less than that of $\left(k_{6} / k_{5}\right)^{1 / 2}$. When the high mixing ratio profile of nitrogen oxides is used, $F_{\varphi} \mathrm{X}$ 
becomes more important than $A_{\varphi}{ }^{2}$ in determining the ozone density between 35 and $45 \mathrm{~km}$. Since the temperature dependence of $F \varphi X$ is less than that of $A_{\varphi} \ddot{Z}$, it follows that $\tau_{1}$ is increased at heights where nitrogen reactions are more important than pure $O$ reactions in determining ozone density.

Figure 10 shows $\tau_{1}$ for the $N+H+O$ (low) case when three different sets of rates for reactions (5) and (6) and two values for 0 , fast and slow are used. Above $35 \mathrm{~km}$ eq. (94) still holds,

$$
\sigma_{1} \approx \beta a\left(1-\frac{180^{\circ}}{\bar{T}}\right)
$$

Since the equilibrium temperature varies with different sets of rates for reactions (5) and (6) (Figure 7 ), so does $\sigma_{1}$.

As discussed in section 4 , the effect of varying rates for reactions (7)-(18) can be shown by varying the water vapor mixing ratio or the mixing xatio of nitrogen oxides. Resulting values of $\tau_{1}$ are within the range of those shown in Figures 9 and 10.

In section 4 we found that the equilibrium temperature calculated had the best match with the observed temperature for the case with set 1 for the rates for reactions (5) and (6), the cooling time scale cf $a^{-1}=10$ days, a water vapor mixing ratio of $5 \cdot 10^{-7}$, and a nitrogen oxides mixing ratio defined by Profile 7 . Using these parameters in the present calculations we find that the minimum value of $\tau_{1}$ is 
2.6 days at $32 \mathrm{kn}$. Between 35 and $61 \mathrm{~km}$ the value of $\tau_{1}$ is between 3.3 and 3.7 dars. Since $\sigma_{1}$ is proportional to ' $a$ ', the revisions suggested in section $4 a$ will lead to further reductions of $\tau_{1}$.

- The results show that coupling between radiative and photochemical processes leads to an acceleration of thermal relaxation above $30 \mathrm{~km}$ for a wide range of reaction rates and other parameters. The minimum value of $\tau_{1}$ is between 2 and 4 days at $31-35 \mathrm{~km}$. When the hydroger reactions are neglected $\tau_{1}$ is nearly constart with height above $40 \mathrm{~km}$ and when the hydrogen reactions are included with a mixing ratio of $5 \cdot 10^{-6}$ for water vapor $\tau_{1}$ increases almost inearly from the minimum value at $35 \mathrm{~km}$ to about 5 days at $61 \mathrm{~km}$. Therefore the Newtonian cooling rate coefficient to be used in the temperature equation for cynamical problems in the stratosphere above $30 \mathrm{~km}$ is not ' $a$ ' but $\tau_{1}^{-1}$. Horeover $\tau_{1}^{-1}$ seems large enough to dissipate internal Rossby waves. 
6. CONCLUSIONS

In this paper we have developed quantitatively justifiable simple models for the radiative heating and the complicated ozone photochemistry of the stratosphere between about 20 and $60 \mathrm{~km}$. These models permit the irmediate evaluation of the effects of various chemical and physical quantities on the temperature and ozone distributions in the stratosphere. We show that the region $35-60 \mathrm{~km}$ should (away from arctic regions) be in approximately joint radiative-photochenical equilibrium, and we use our simple models to calculate this equilibrium. We show that the interaction of radiation and chemistry significantly: buffers the temperature and ozone distributions in the stratosphere so that rather large changes in cooling rates, reaction rates, ctc., Jeá to much more modest changes in ozone and temperature. We also show that given an observed distribution of mean temperature (a quantity much wore extensively measured than ozone) we can (assuming accurate knowledge of reaction and infrared cooling rate coefficients) determine the amounts of water vapor and nitrogen oxides needed to produce the ozone distribution which would in turn lead to the observed temperature. This procedure is facilitated by the fact (which we demonstrate) that hydrogen reactions are significant loss processes for ozone above $40 \mathrm{~km}$ while nitrogen reactions are important below $50 \mathrm{~km}$. Thus there are regions where nitrogen and hydrogen reactions are individually rather than jointly important. Unfortunately, reaction and cooling rate coefficients are not accurately known. However, our simplified equations can st11l be used as diagnostic tools. In. this manner, we show that an 
internally consistent description of observed distributions of temperature and ozone in the stratosphere can be obtalned with a time scale for infrared cooling varying from ten days at $35 \mathrm{~km}$ to 7.7 days above $40 \mathrm{~km}$, a mixing ratio for nitrogen oxides $\left(\mathrm{NO}+\mathrm{HO}_{2}\right)$ of about $2-3 \cdot 10^{-8}$ and a mixing ratio for water of about $3 \cdot 10^{-6}$. The question of nomal No ${ }_{x}$ mixing ratio has assumed considerable importance recently because it is believed that proposed SST (super sonic transport) operations may add about $1 \cdot 10^{-9}$ to the $\mathrm{NO}_{\mathrm{x}}$ mixing ratio. The present calculations suggest that the SST contribution will be only $3-5 \%$ of the ambient amount, and because of the thermal buffering of the system the effect of this addition on ozone density should be less than $3-5 \%$.

We also used our simple models to calculate the joint radiativephotochenical relaxation of perturbations in temperature, ozone mixing ratio and hydroxyl mixing ratio away from their equilibrium values. We find that for all photochemical models considered, the photochemistsy greatly accelerates thermal relaxation as calculated simply on the basis of infrared cooling. The time scale for the latter is about 10 days. The actual time scale for thermal relaxation when photochemistry (which is temperature dependent) is included proves to be only 2-4 days. These shorter scales imply greatly enhanced damping for hydrodynamic waves in the stratosphere. 


\section{ACKNOWLEDGRINTS}

The buik of this work has been supported by grant number GA-25904 of the National Science Foundation and grant number NGR-14-001-193 of: the National Aeronautics and Space, Administration, both at the . University of Chicago. Additional support was received under grant number NSF GA $33990 X$ of the National Science Foundation at Harvard University. Computations were performed at the National Certer for Atmospheric Research which is supported by the National Science Foundation. Useful conversations with $S$. Wofsy are also gratefully acknowledged. 


\section{REFERENCES}

Barth, Charles A., "Nitric Oxide in the Upper Atmosphere," Annales de Geophysique, Vol. 22, No. 2, Lille, France', April-June 1966, pp. $198-207$

Bension, Sidney W., and Axworthy, Arthur E., "Reconsideration of the Rate Constants From the Thermal Decomposition of Ozoni," Iournal of Chemical Physics, Vol. 42, No. 7, 1 April 1965, pp. 2614-26i5. Berces, T. and Förgeteg, S., "Kinetics of Photolysis of Nitric Acid Vapour, Part 2, Decomposition of Nitric Acid Vapour Photosensitized By Nitrogen Dioxide," Transactions of the Faraday Society, Vol. 66, No. 567, Part 3, London, England, March 1970, pp. 640-647.

Brinkmann, R. T., "Dissociation of Water Vapor and Evolution of Oxygen in the Terrestrial Atmosphere," Journal of Geophysica?

: Research, Vol. 74, No. 23, 20 October 1969, pp. 5355-5368. Brinkmann, R. T., Green, A. E. S., and Barth, Charles A., "itA Digitalized Solar Ultraviolet Spectrum," Technical Report No. 32-951, Jet Propulsion Laboratory, California Institute of Technology, Pasadena, California, 15 August 1966, 73 pp. Charney, Jule G., and Drazin, Philip G., "Propagation of PlanetaryScale Disturbances From the Lower into the Upper Atmosphere," Journal of Geophysical Research, Vol. 66, No. 1, January 1961, pp. 83-109. 
Crutzen, Paul J., "Ozone Production Rates in an Oxygen-HydrogenNitrogen Oxide Atmosphere," Journal of Gcophysical Rescarch, Oceans and Atmospheres, Vol. 76, No. 30, 20 October 1971, pp. $7311-7327$.

Demore, W. B., and Raper, O: F., "Reaction of $O(' D)$ With Methare,". Journal of Chemical Physics, Vol. 46, No. 7, 1 April 1967, pp. $2500-$ 2505.

Dickinson, Robert E., "On'the Excitation and Propagation of Zonal Winds in an Atmosphere With Newtonian Cooling, "Journal of the Atmospheric Sciences, Vol. 25, IJo. 2; March 1968, pp. 269-27\%.

Dickinson, Robert E., "Vertical Propagation of Planetary Rossby itaves Through an Atmosphere With Newtonian Cooling," Journal of Geophysical Research, Vol. 74, No. 4, 15 February 1969, pp. 929-ij8.

Dozovan, R. J., and Husain, D., "Recent Advances in the Chemisiry of Electronically Excited Atoms," Chemical Reviews, Vol. 70, No. 4, fiugust 1.970, pp. 489-516.

Dütsch, H. U., "The Photochemistry of Stratospheric Ozone," Quarterly Journal of the Royal Meteorological Socicty, Vol. 94, No. 402, London, England, October 1968, pp. 483-497.

Greiner, N. R., "Hydroxal Radical Kinetics by Kinetic Spectroscopy, III; Reactions With $\mathrm{H}_{2} \mathrm{O}_{2}$ in the Range $300^{\circ}-458^{\circ} \mathrm{K}$, " Journal of Physical Chemistry, Vol. 72, No. 2, February 1968, pp. 857-859. 
Griggs, M. , "Absorption Coefficients of Ozone in the Ultraviolet and Visible Regions, "Jourmal of Chemical Physics, Vol. 49, No. 2, 15 July 1968 , pp. $857-859$.

Hall, Jr., T. C., and Blacet, F. E., "Separation of the Absorption Spectra of $\mathrm{NO}_{2}$ and $\mathrm{N}_{2} \mathrm{O}_{4}$ in the Range 2400-5000 \&, "Iournal of Chemical Physics, Vol. 20, No. 11, November 1952, pp. 1745-1749. Hilsenrath, Ernest, Seiden, Lester, and Goodman, Philip, "An Ozone Measurement in the Mesosphere and Stratosphere by Means of a Rocket Sonde," Journal of Geophysical Research, Oceans and Atroospheres, Vol. 74, No. 28, 20 December 1969, pp. 6873-6880.

Hinteregger, H. E., "The Extreme Ultraviolet Solar Spectrum and its Variation During a Solar Cycle," Annales de Gcophysique, Vol. 26, No. 2, Iille, France, April-June 1970, pp. 547-554. .

Holt, R. B., McLane, C. K., and Oldenberg, O., "Ultraviolet Absorption Spectrum of Hydrogen Peroxide, "Journal of Chemical Physics, Vol. 16, No. 3, March 1948, pp: 225-229.

Holton, James R., "A Diagnostic Model for Equatorial Wave Disturbances: The Role of Vertical Shear of the Mean Wind, "Journal of the Atmospheric Sciences, Vol. 28, No. 1, January 1971, pp. $55-64$

Hudson, R. D., Carter, V. L., and Breig, E. J., "Predissociation in the Schumann-Runge Band System of $\mathrm{O}_{2}$ : Laboratory Measurenents and Atmospheric Effects," Journal of Geophysical Research, Space 
Physics, Vol. 74, No. 16, 1 August 1969, pp. 4079-4087.

Hunt, B. G. , "Photochemistry of Ozone in a Moist Atmosphere, "Journal of Gcophysical Research, Vol. 71, No. 5, 1 March 1966, pp. 1385-1398.

Inin, Edward C. Y., and Tanaka, Yoshio, "Absorption Coefficient of Ozone in the Ultraviolet and Visible Regions," Journal of the Optical Society of America, Vol. 43, No. 10, October 1953, pp. 870-873.

Jefferys, Sir Harold, "The Instability of a Compressible Fluid Heated Below," Procecdings of the Cambridge Philosophical Society, Vol. 26, Part 2, London, England, April 1930, pp. 170-172.

Johnson, Francis S., Purcell, James, D., and Tousey, Richard, "Stucites of the Ozone Layer Above New Mexico, "Rocket Exploration of the Upper Atmosphere, ed. R. L. S. Boyd and M. J. Seaton, Pergamon Press, London, England, 1954, pp. 189-199. Johnston, Harold, "Laboratory Chemical kinetics as an Atmospineric Science", Proceedings of the Survey Conference, February 15-16, 1972 , Climatic Impact Assessment Program, A. E. Barrington, editor. Department of Transportation report DOT-TSC-0ST-72-13. Available through National Technical Information Service, Springficld, Virginia 22151, pp. 90-114.

Johnston, Harold S., and Yost, Don M., "The Kinetics of the Rapid Gas Reaction Between Ozone and Nitrogen Dioxide, "Journal of Chemical Physics, Vol. 17, No. 4, April 1949, pp. 386-392. 
Junge, C. E., "Gases," Air Chemistry and Radinactivity, ed. I. Van Mieghem, Vol. 4, Academic Press, New York, 1963, Chapter 1, p. 37.

Kaufman, Fredrick, "Neutral Reactions," DASA Reaction Rate Handbook, 1967, Chapter 14, pp. 1-17.

Kaufman, Fredrick, "Neutral Reactions Involving Hydrogen and Other Minor Constituents," Canadian Journal of Chemistry, Vol. 47, No. 10, Ottawa, Canada, 15 May 1969, pp. 1917-1926.

Klein, Fritz S., and Herron, John T., "Erratum: Mass-Spectrometr.: Study of the Reactions of $\mathrm{O}$ Atoms with $\mathrm{NO}$ and $\mathrm{NO}_{2}$, "Journal of Chemical Physics, Vol. 44, No. 9, 1 May 1966, pp. 3645-3646. Kondratyev, K. Ya., Radiation in The Atmosphere, International Geophysics Series, Vol. 12, Academic Press, New York 196C, 912 pp. Leovy, Conway, "Radiative Equilibrium of the Mesosphere", Journal of the Atmospheric Sciences, Vol. 21, No. 3, Nay 1964a, pp. 238-248. Leovy, Conway, "Simple íodels of Thermally Driven Mesospheric Circulation", Joumal of the Atmospheric Sciences, Vol. 21, No. 4, July 1964b, pp. 327-341.

Leovy, Conway B., "Atmospheric Ozone: An Analytic Model for Photchemistry in the Presence of Water Vapor, "Journal of Gcophysical Research, Vol. 74, No. 2, 15 January 1969a, pp. 417-426. 
Leovy, Conway B., "Energetics of the Middle Atmosphere," Advances in Geophysics, Vol. 13, Academic Prcss, New York, 1969b, pp. 191221.

Lindzen, Richard $S$. and Blake, Donna, "Internal Cravity Waves in Atmosnheres with Roalistic Missination and rerperature Part II.

Thermal Tides Excited Below the Mesopause", Geophysical Fluid Dynamics, vol. 2, No. 1, 1971, pp. 31-61.

Lindzen, Richard S. and Goody, Richard, "Radiative and Photochemical Processes in Mesospheric Dynamics: Part I, Models for Radiative and Photochemical Processes, "Journal of the Atmospheric Scienc 25 , Vol. 22, No. 4, July 1965, pp. 341-348.

Mastenbrook, H. J., "Water Vapos: Distribution in the Stratosphere and High Troposphere, "Journal of the Atmospheric Sciences, Vol. 25, No. 2, March 1968, pp. 299-311.

Miller, D. E., and Stewart, K. H. "Observations of Atmospheric Ozone," Proceedings of the Royal Socicty of London, Series A, Vol. 288, No. 1415, England, 30 November 1965, pp. 540-544.

Murgatroyd, R. J., and Goody, Richard M., "Sources and Sinks of Radiative Energy From 30 to $90 \mathrm{~km}$, "Quarterly Journal of the Royal Meteorological Society, London, England, Vol. 84, No. 361, July 1958, pp. $205-234$. 
Nakayama, Toshio, Kitamura, Morris Y., and Watanabe, K., "Ionization Potentia? and Absorption Cocfficients of Nitrogen Dioxide," Journal of Chemical Physics, Vol. 30, No. 5, May 1959, pp. $1180-$ 1186.

Nicolet, M., "Ozone and Hydrogen Reactions," Annales de Geophysique, Vol. 26. No. 2, Lille, France, April-June 1970, pp. 547-554.

Ogura, Yoshimitsu, and Philiips, Norman A., "Scale Analysis in Deep and Shallow Convection in the Atmosphere," Journal of the Atmosplucric Sciences, Vol. 19, No. 2; March 1962, pp. 173-179.

Pearce, Jeffery B., "Rocket Measurement of Nitric Oxide Between óo and $96 \mathrm{~km}, "$ Journal of Geophysical Reseaxch, Space Physics, Vol. 74, No. 3, 1 Narch 1969, pp. 853-861.

Phillips, L. F. and Schiff, II. I., "Mass Spectrometric Studies of - Atomic Reactions. III Reactions of Hydrogen with Nitrogen Dioxide and with Ozone", Joumal of Chemical Physics, Vol. 37, No.6, September 1962, pp. 1233-1238.

Plass, Gilbert N., "The Influence of the 9.6 Micron Ozone Band on the Atmospheric Infra-Red Cooling Rate," Quarterly Journal of the Royal Meteorological Society, London, England, Vol. 82, No. 351, January 1956, pp. 30-44. 
Rawcliffe, R. D., Meloy, G. E., Friedman, R. M., and Rodgers E. H. "Measurement of Vertical Distribution of Ozone From a Polar Orbiting Satellite, "Journal of Gcophysicall Research, Vol. $6 \varepsilon$, No. 24, 15 December 1963, pp. 6425-6429.

Rodgers, C. D., and Walshaw, C. D., "The Computation of Infrared Cooling in Planetary Atmospheres, "Quarterly Journal of the Royal Meteorological Society, London, England, Vol. 92, No..392, January 1966, pp. 67-92.

Schiff, H. I. "Neutral Reactions Involving Oxygen and Nitrogen," Canadian Journal of Chemistry, Vol. 47, No. 10,' Ottawa, Canáa, 15 May 1969, pp. 1903-1916.

Schofield, K., "An Evaluation of Kinetic Rate Data for Reactions of Neutrals of Atmospheric Interest," Planetary and Spacc Scienc.'s. - Vol. 15, No. 4, Oxford, England, April 1967, pp. 643-670. Schölz, T. G., Ehhalt, D. H., Heidt, L. E., and Martell, E. A., "Water Vapor, Molecular Hydrogen, Methane, and Tritium Concentrations Near the Stratopause," Journal of Geophysical Research, Vol. 75, No. 15, 20 May 1970, pp. 3049-3054.

Schitz, K., Junge, C., Beck, R., and Albrecht, B., "Studies of Atmospheric $\mathrm{N}_{2} \mathrm{O}$, Journal of Geophysical Research, Vol. 75, No. 12, 20 April 1970, pp. $2230-2246$.

Shimazaki, Tatsuo, and Laird, A. R., "A Model Calculation of ine Diurnal Variation in Minor Neutral Constituents in the Mesosphere 
and Lower Thermosphere Including Transport Effects," Jouznal of Geophysical Research, Space Physics, Vol. 75, No. 16, 1 June 1970, pp. $3221-3235$.

Supplementary Atmosphere (Tropical), IJandbock of Gicophysics and Space Environments, ed. Shea L. Valley, Air Force Cambridge Research Laboratories, McGraw-Hill, Nëw York, 1965, pp. 2-11. Theon, J. S., and Smith, W. S., "The Meteorological Structure of the Mesosphere Including Seasonal and Latitudinal Variations," Mesospheric Models and Related Experiments, Proceedings of the Fourth Esrin-Eslab Symposium, Frascati, Italy, 6-10 July 1970, 0 . G. Fiocco, Astrophysics and Space Science Libraxy, Vol, 25, D. Reidel Publishing Company, Dordrecht, Holland, 1971, pp. 131-146. Thompson, B. A., Harteck, P., and Reeves, Jr., R. R., "Ultra'violet Absorption Coefficients of $\mathrm{CO}_{2}, \mathrm{CO}, \mathrm{O}_{2}, \mathrm{H}_{2} \mathrm{O}, \mathrm{N}_{2} \mathrm{O}, \mathrm{NH}_{3}$ ' NO, $\mathrm{SO}_{2}$, and $\mathrm{CH}_{4}$ Between 1850 and $4000 \AA$, "Journal of Geophysicàl Research, Vol. 68, No. 24, 15 December 1963, pp. 6431-6436. Van Allen, J. A. and Hopfield, J. J., "Preliminary Report on Atmospheric Ozone Heasurements from Rockets", Soci.eté Royale des Sciences de Liege - Micmoires, Vol. 12, Belgium, 1952, pp. 179-183.

Watanabe, K., and Zelikoff, Murray, "Absorption Cogfficients of Water Vapor in the Vacuum Ultraviolet," Journal of the Optical Socicty of America, Vol. 43, No. 9, September 1953, pp. 753-755. 
Weeks, L. H., and Smith, L. G., "A Rocket Mcasurement of Ozone Near Sunrize," Planetary and Space Science, Vol. 16, No. 9. Oxford, England, September 1968, pp. 1189-1195. Wofsy, Steven C., McConnel1, John C., and McElroy, Michael B., "Atmosnherfe $\mathrm{CH}_{4}$, $\mathrm{CO}$, and $\mathrm{CO}_{2}$ ", Jnumal of Geophvsical Research. Vol. 77, No. 24, August 1972 , pp. $4477-4493$.

Zipf, E. C., "The Collisional Deactivation of Metastable Atoms and Molecules in the Upper Atmosphere," Canadian Journal of Chemistry, Vol. 47, No. 10, Ottawa, Canada, 15 May 1969, pp. 1863-1877. 
Table 1

Reaction

i. $\mathrm{O}_{2}+\mathrm{h} \nu \rightarrow \mathrm{O}+\mathrm{O}$

2a. $\mathrm{O}_{3}+\mathrm{h \nu} \rightarrow \mathrm{O}+\mathrm{O}_{2}$

2b. $\mathrm{O}_{3}+\mathrm{h} v \rightarrow \mathrm{O} * \dot{\mathrm{O}_{2}}$

3. $\mathrm{H}_{2} \mathrm{O}+\mathrm{hV} \rightarrow \mathrm{H}+\mathrm{OH}$

4. $\mathrm{NO}_{2}+\mathrm{h} \nu \rightarrow \mathrm{NO}+\mathrm{O}$

5. $\mathrm{O}+\mathrm{O}_{2}+\mathrm{M} \rightarrow \mathrm{O}_{3}+\mathrm{M}$

6. $\mathrm{O}+\mathrm{O}_{3} \rightarrow 2 \mathrm{O}_{2}$

7. $\mathrm{O} * \mathrm{M} \rightarrow \mathrm{O}+\mathrm{M}$

8. $\mathrm{O} *+\mathrm{H}_{2} \mathrm{O} \rightarrow 2 \mathrm{OH}$

9. $\mathrm{OH}+\mathrm{O} \rightarrow \mathrm{H}+\mathrm{O}_{2}$

10. $\mathrm{H}+\mathrm{O}_{2}+\mathrm{M} \rightarrow \mathrm{HO}_{2}+\mathrm{M}$

11. $\mathrm{HO}_{2}+\mathrm{O} \rightarrow \mathrm{OH}+\mathrm{O}_{2}$

12. $\mathrm{OH}+\mathrm{O}_{3} \rightarrow \mathrm{HO}_{2}+\mathrm{O}_{2}$

13. $\mathrm{OH}+\mathrm{OH} \rightarrow \mathrm{H}_{2} \mathrm{O}+\mathrm{O}$
Rate

$\mathrm{q}_{2}(\lambda<2460 \AA)$

$q_{3 a}(3100 \AA<\lambda(11000 \AA)$

$\mathrm{q}_{3 \mathrm{~b}}(\lambda<3100 \AA)$

$\mathrm{q}_{\mathrm{H}_{2} \mathrm{O}}(\lambda(2400 \AA)$

$\mathrm{q}_{\mathrm{NO}_{2}}(\lambda<3975 \AA)$

$\left.k_{6}^{k_{5}}\right\}$ see Table 2

$k_{7}=5 \cdot 10^{-11}$

$k_{8}=5 \cdot 10^{-11}$

$k_{9}=5 \cdot 10^{-11}$

$k_{10}=4 \cdot 10^{-32}$

$k_{11}=5 \cdot 10^{-11}$

$\mathrm{k}_{12} \cdot 1 . \cdot 10^{-12} \mathrm{~T}^{3 / 2} \exp (-1500 / \mathrm{T}) \quad$ Nicolet 1970

$k_{13}=5 \cdot 10^{-13} T^{1 / 2} \exp (-1000 / T) \quad$ Nicolet 1970

\section{Source}

See text

See text

See text

See text

See text

See Table 2

See Table 2

Zipf 1969

Demore and Raper 1967

Kaufman 1969

Kaufmen 1969

Nicolet 1970 
Table 1 (Cont'd.)

\section{Reaction}

14. $\mathrm{OH}+\mathrm{HO}_{2} \rightarrow \mathrm{H}_{2} \mathrm{O}+\mathrm{O}_{2}$

15. $\mathrm{HO}_{2}+\mathrm{NO} \rightarrow \mathrm{OH}+\mathrm{NO}_{2}$

16. $\mathrm{NO}_{2}+\mathrm{O} \rightarrow \mathrm{NO}+\mathrm{O}_{2}$

17. $\mathrm{NO}+\mathrm{O}_{3} \rightarrow \mathrm{NO}_{2}+\mathrm{O}_{2}$

18. $\mathrm{NO}_{2}+\mathrm{O}_{3} \rightarrow \mathrm{NO}_{3}+\mathrm{O}_{2}$

19. $\mathrm{NO}_{2}+\mathrm{OH}+\mathrm{M} \rightarrow \mathrm{HNO}_{3}+\mathrm{M}$

20. $\mathrm{NO}+\mathrm{OH}+\mathrm{M} \rightarrow \mathrm{HNO}_{2}+\mathrm{M}$

2.. $\mathrm{HNO}_{3}+\mathrm{O} \rightarrow \mathrm{NO}_{3}+\mathrm{OH}$

22. $\mathrm{HNO}_{2}+\mathrm{O} \rightarrow \mathrm{OH}+\mathrm{NO}_{2}$

23. $\mathrm{NO}_{3}+\mathrm{NO} \rightarrow 2 \mathrm{NO}_{2}$

24. $\mathrm{HO}_{2}+\mathrm{HO}_{2} \rightarrow \mathrm{H}_{2} \mathrm{O}_{2}+\mathrm{O}_{2}$

25. $\mathrm{H}_{2} \mathrm{O}_{2}+\mathrm{hv} \rightarrow 2 \mathrm{OH}$

26. $\mathrm{H}_{2} \mathrm{O}_{2}+\mathrm{OH} \rightarrow \mathrm{H}_{2} \mathrm{O}+\mathrm{HO}_{2}$

27. $\mathrm{H}+\mathrm{O}_{3} \ldots \mathrm{OH}+\mathrm{O}_{2}$
Rate

$\ddot{k}_{14}=10^{-11}$

$k_{15}=3 \cdot 10^{-12} T^{1 / 2} \exp (-1250 / T)$

$k_{16}=3.2 \cdot 10^{-11} \exp (-300 / \mathrm{T})$

$k_{17}=1.7 \cdot 10^{-12} \exp (-1310 / \mathrm{T})$

$k_{18}=10^{-11} \exp (-3500 / \mathrm{T})$

$k_{1.9}=3.3 \cdot 10^{-33}$

$k_{20}=k_{19}$

$k_{21}=1.7 \cdot 10^{-11}$

$k_{22}=k_{21}$

$k_{23}=10^{-11}$

$k_{24}=5 \cdot 10^{-12} \exp (-1000 / \mathrm{T})$

$\lambda<5650 \AA$

$\mathrm{k}_{26}=4.10^{-13} \mathrm{~T}^{1 / 2} \exp (-600 / \mathrm{T})$

$k_{27}=1.5 \cdot 10^{-12} \mathrm{~T}^{1 / 2}$
Source

\section{Kaufman 1969}

Nicolet 1970

Klein and Herron 1966.

Schofield 1967

Johnston and Yost 1949

Berces and Förgeteg 1970

See text

Berce's and Förgeteg 1970

See text

Berces and Förgeteg 1970

Nicolet 1970

Holt 1948

Greines: $1968^{\circ}$

Fhillips and Schiff 1962 
Table 2

Set 1:

$\left.k_{5}=1.2 \cdot 10^{-35} \exp (1000 / T)\right)$

$k_{6}=2.0 \cdot 10^{-11} \exp (-2395 / \mathrm{T})$

Schiff 1969

Set 2:

$k_{5}=8 \cdot 0 \cdot 10^{-35} \exp (445 / T)$ ?

$\left.k_{6}=5.6 \cdot 10^{-11} \exp (-2850 / T)\right\}$

Benson and Axworthy 1965

\section{Set 3:}

$\left.\begin{array}{l}k_{5}=5.5 \cdot 10^{-34}(300 / \mathrm{T})^{2.6} \\ k_{6}=1.4 \cdot 10^{-12} \exp (-1500 / \mathrm{T})\end{array}\right\}$ Kaufman 1967 
Table 3

Nitrogen Oxides Profile

Nitrogen Oxides Mixing

Ratio at Stratopause

Temperature at Stratopause $\left({ }^{\circ} \mathrm{K}\right) 304$

Temperature at Stratopause

(Daily Mean $)\left({ }^{\circ} \mathrm{K}\right)$

12

$$
6.4 \cdot 10^{-9} \quad 8.8 \cdot 10^{-8} \quad 3 \cdot 10^{-9} \quad 3 \cdot 10^{-8} \quad 10^{-7} \quad 1.4 \cdot 10^{=8} \quad 1.6 \cdot 10^{-7} \quad 0
$$

$291 \quad 306$

$301 \cdot 291 \quad 303$

$288 \quad 307$

273

290 
Figure Legends

Figure 1. The absorption of solar photons by $\mathrm{NO}_{2}, \mathrm{O}_{2}, \mathrm{H}_{2} \mathrm{O}$, and $\mathrm{O}_{3}$ as a function of height.

Figure 2. The radiative-photochemical equilibrium temperature at $0^{\circ}$ latitude as a function of height. The six cases are described in section 4.

Figure 3. The radiative-photochemical equilibrium ozone number density at $0^{\circ}$ latitude as a function of height.

Figure 4. Same as Figure 2 but at $45^{\circ}$ latitude.

Figure 5. Same as Figure 3 but at $45^{\circ}$ latitude.

Figure 6. The radiative-photochemical equilibrium temperature as a function of height for $0^{\circ}$ latitude for an $\mathrm{N}+\mathrm{H}+\mathrm{O}$ atmosphere.

- The three sets of reaction rates are in Table 2 and the fast and slow cooling ratcs are discussed in the text. Our low $\mathrm{NO}_{\mathrm{x}}$ values were used.

Figure 7. The relaxation time scales in a pure 0 atmosphere. $\mathcal{B}^{-1}$ and $\mathrm{a}^{-1}$ are the relaxation time scales for $\mathrm{O}_{3}$ and temperature, respectively, when the coupling between the photochemistry and temperature is neglected. $\tau_{2}$ and $\tau_{1}$ are the relaxation time scales for the $\mathrm{O}_{3}$ and temperature, respectively, when the coupling is considered. 
Figure 8. The relaxation time scales in an $\mathrm{N}+\mathrm{H}+\mathrm{O}$ atmosphere. $\mathbb{B}^{-1}$. $\mathcal{E}^{-1}$, arr. $a^{-1}$ are the relaxation time scales for $\mathrm{O}_{3} ; \mathrm{OH}$, and temperature, respectively, when the coupling between the photochemistry ard temperature is neglected. $\tau_{2}, \tau_{3}$, and $\tau_{1}$ are the relaxation time scales for $\mathrm{O}_{3}, \mathrm{OH}$, and temperature, respectively, when the coupling is included.

Figure 9. The thermal relaxation time scale, $\tau_{1}$, as a function of height for the cases considered in Figures 2 and 3.

Figure 10. The thermal relaxation time scale, $\tau_{1}$, as a function of height for the cases considered in Figure 6. 


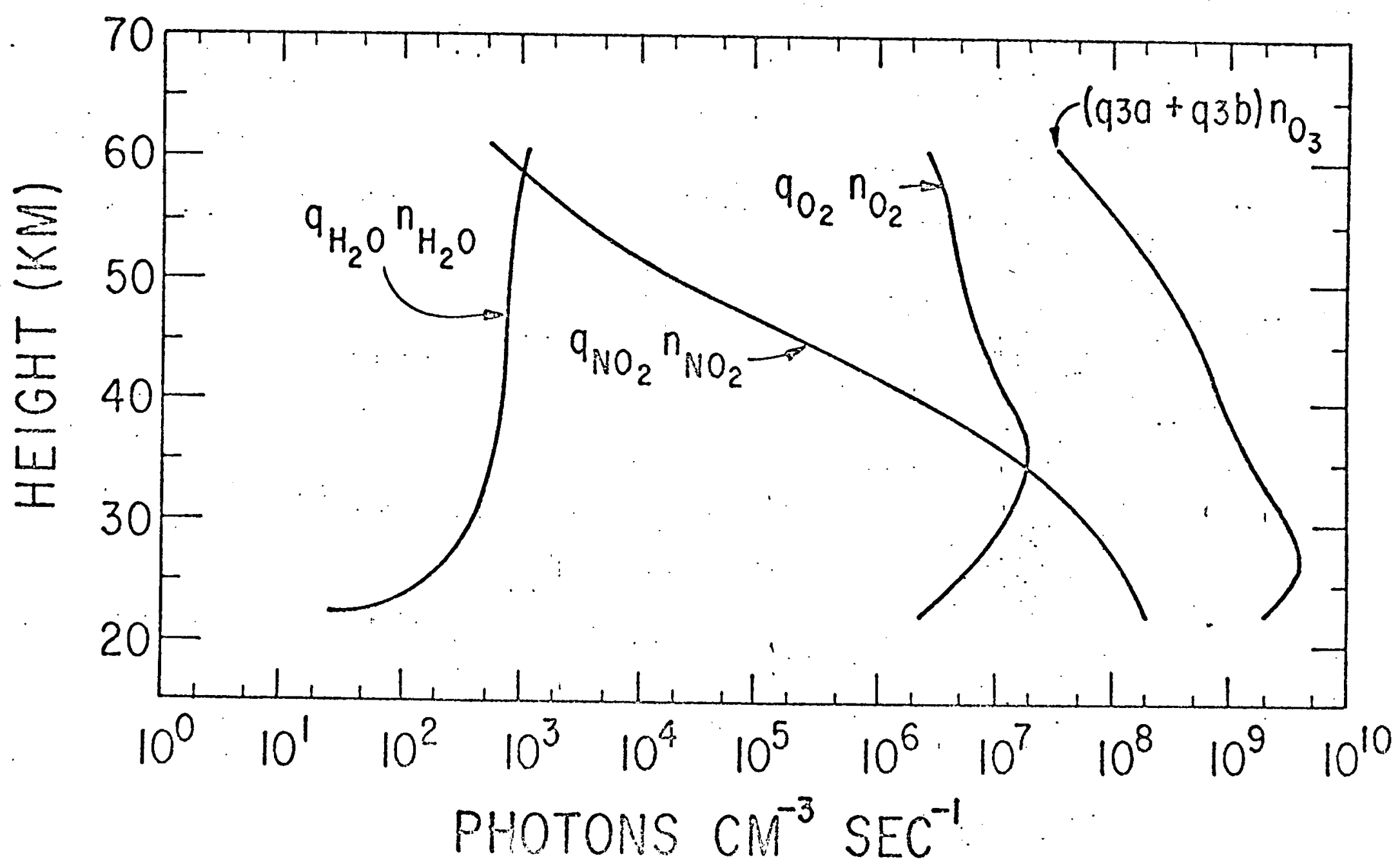




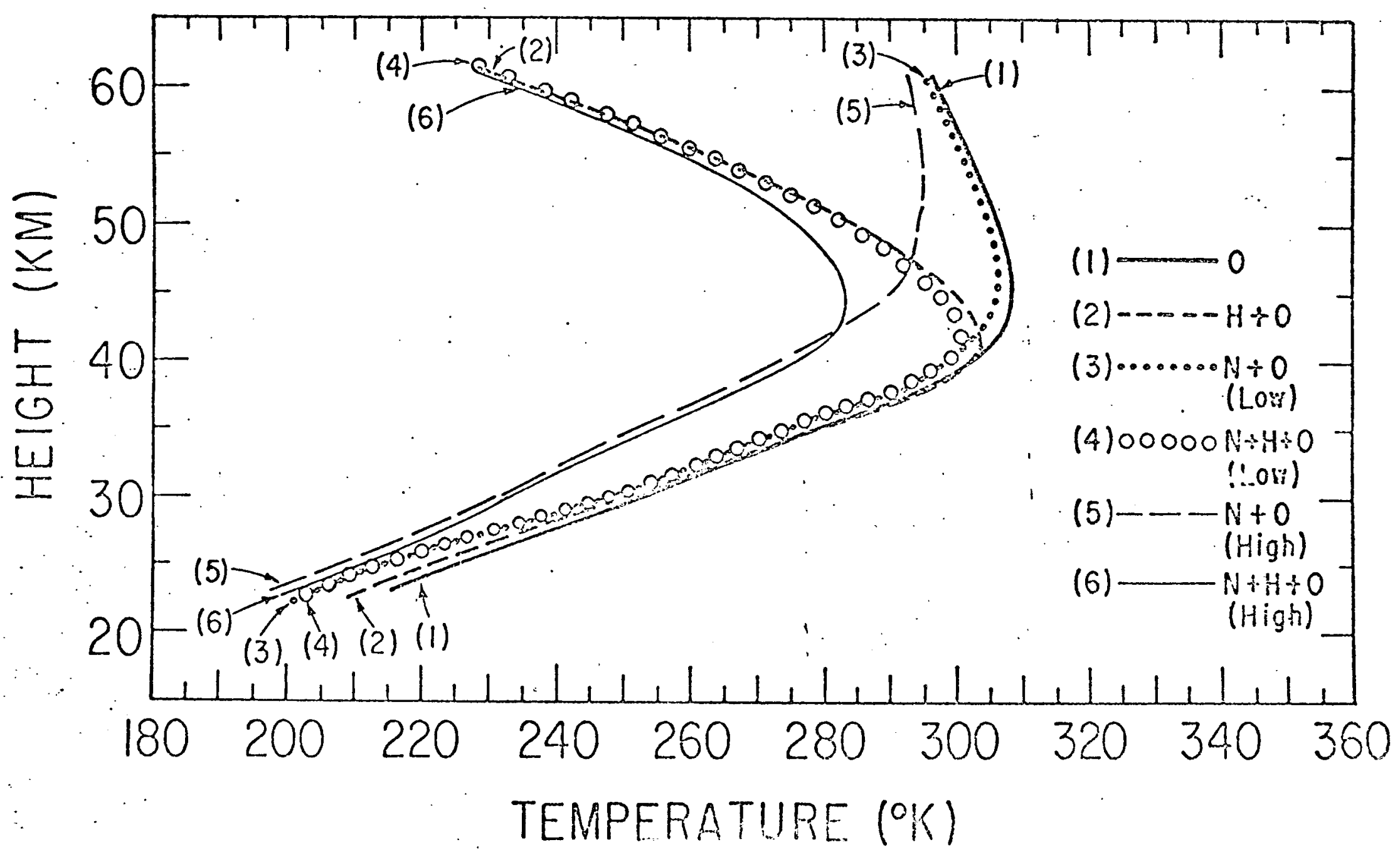




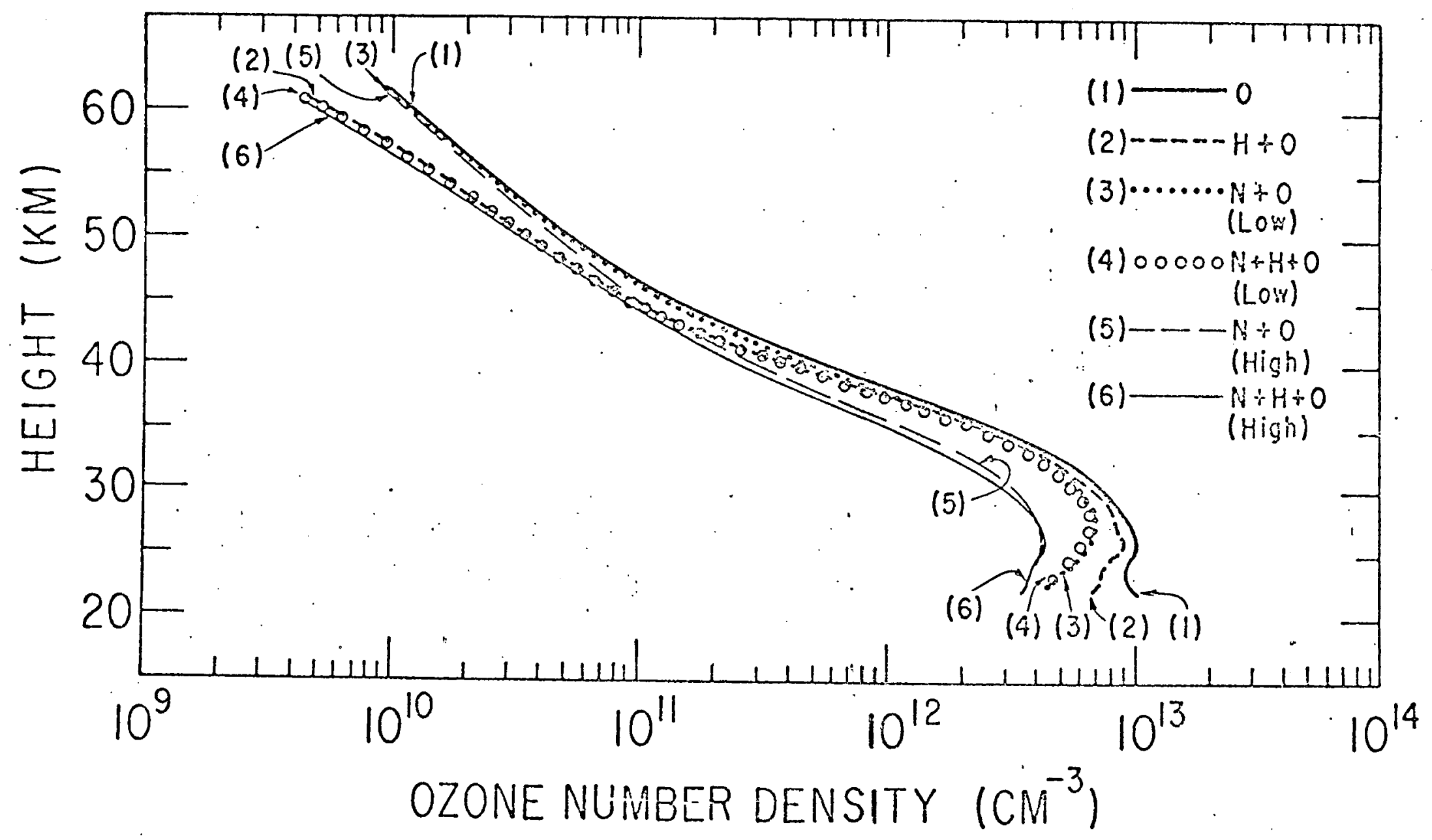




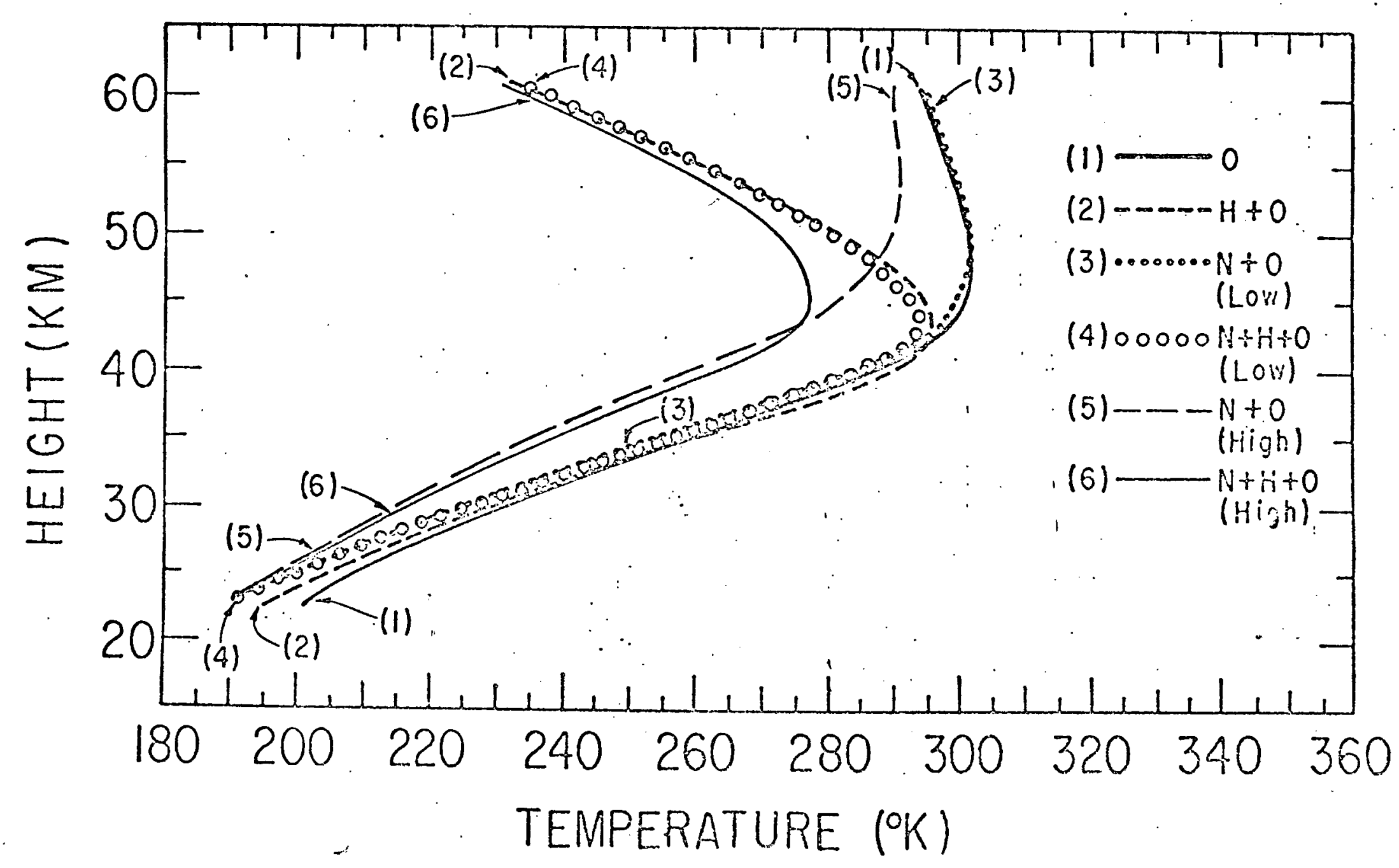




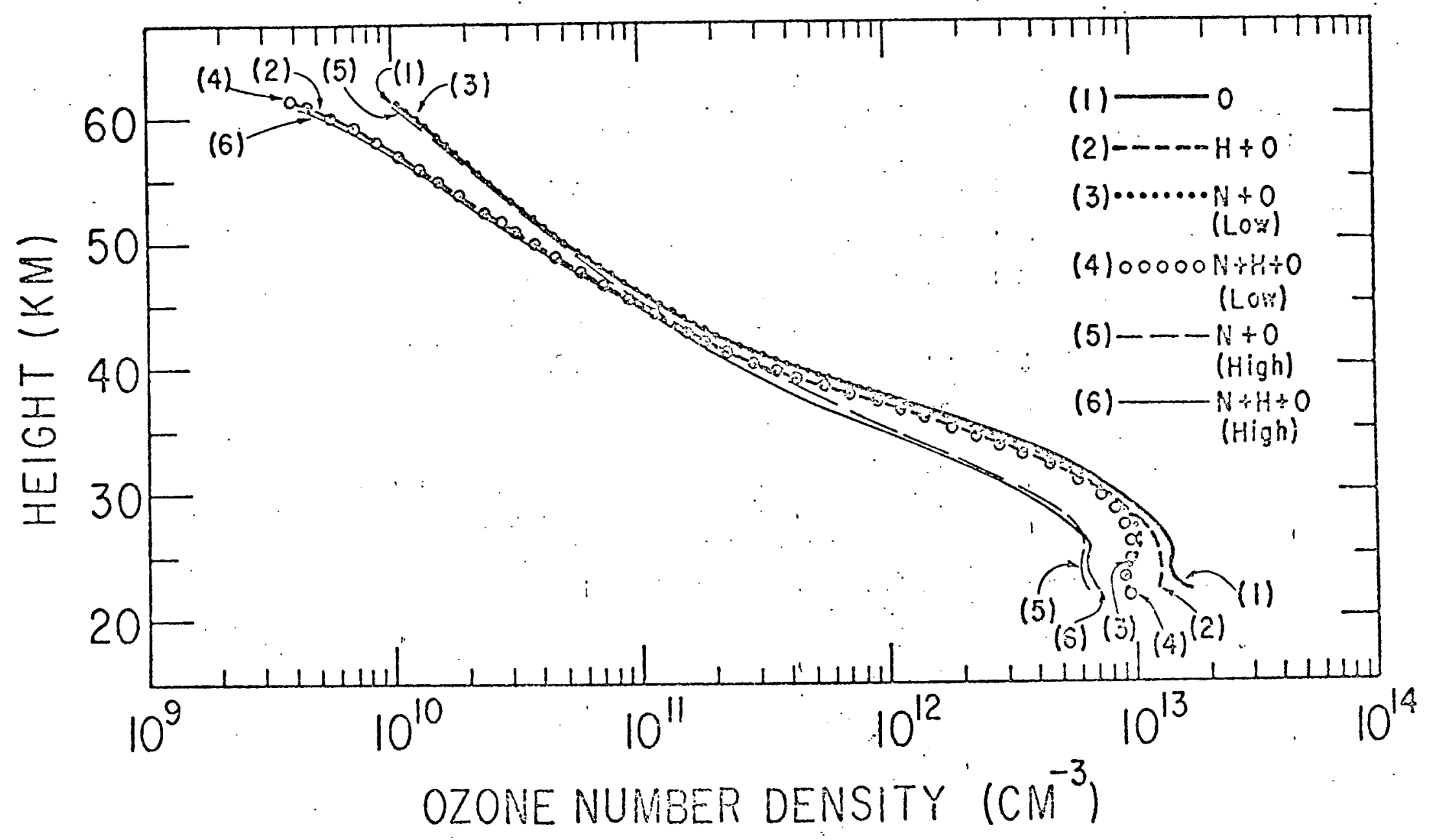




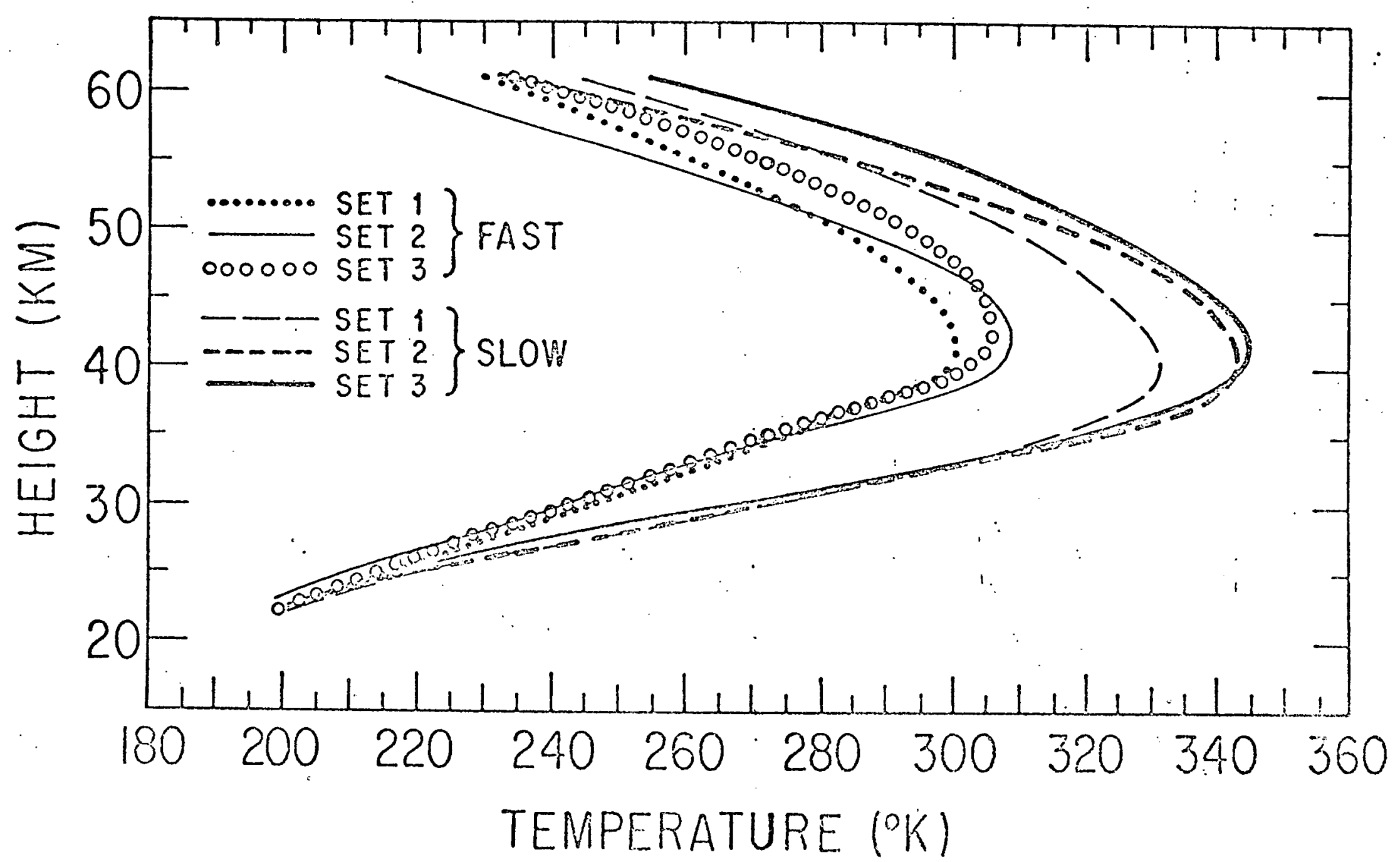




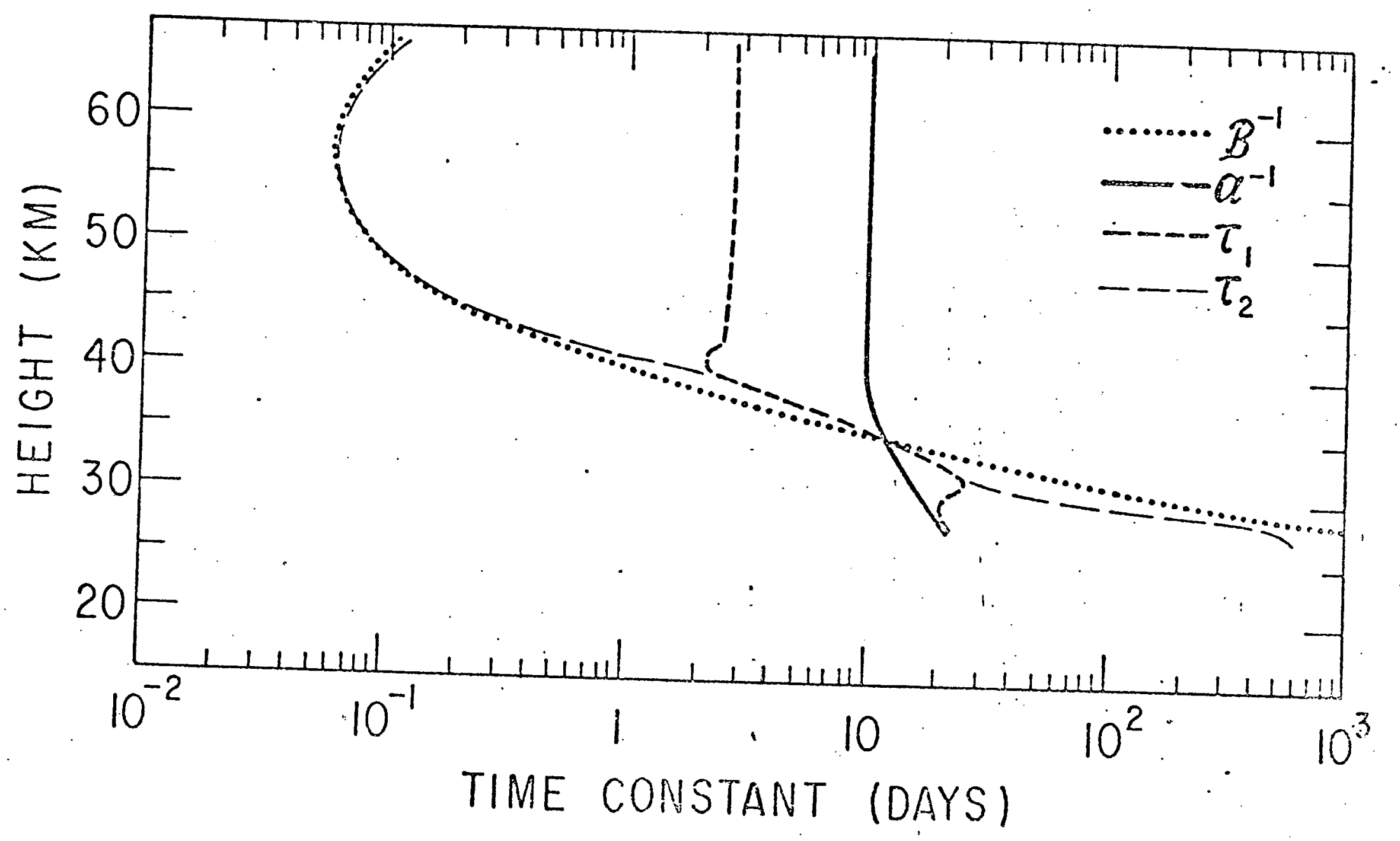




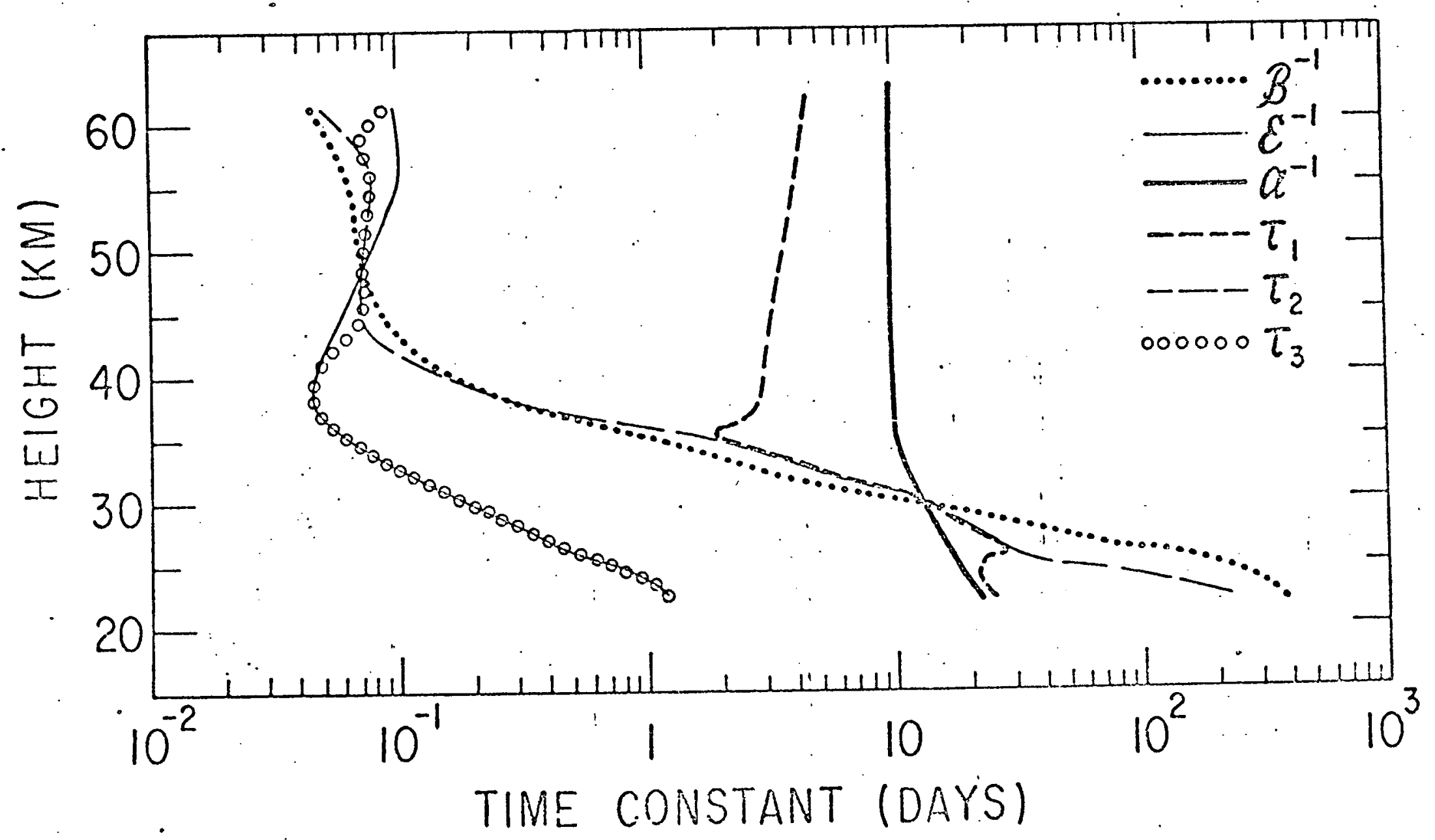




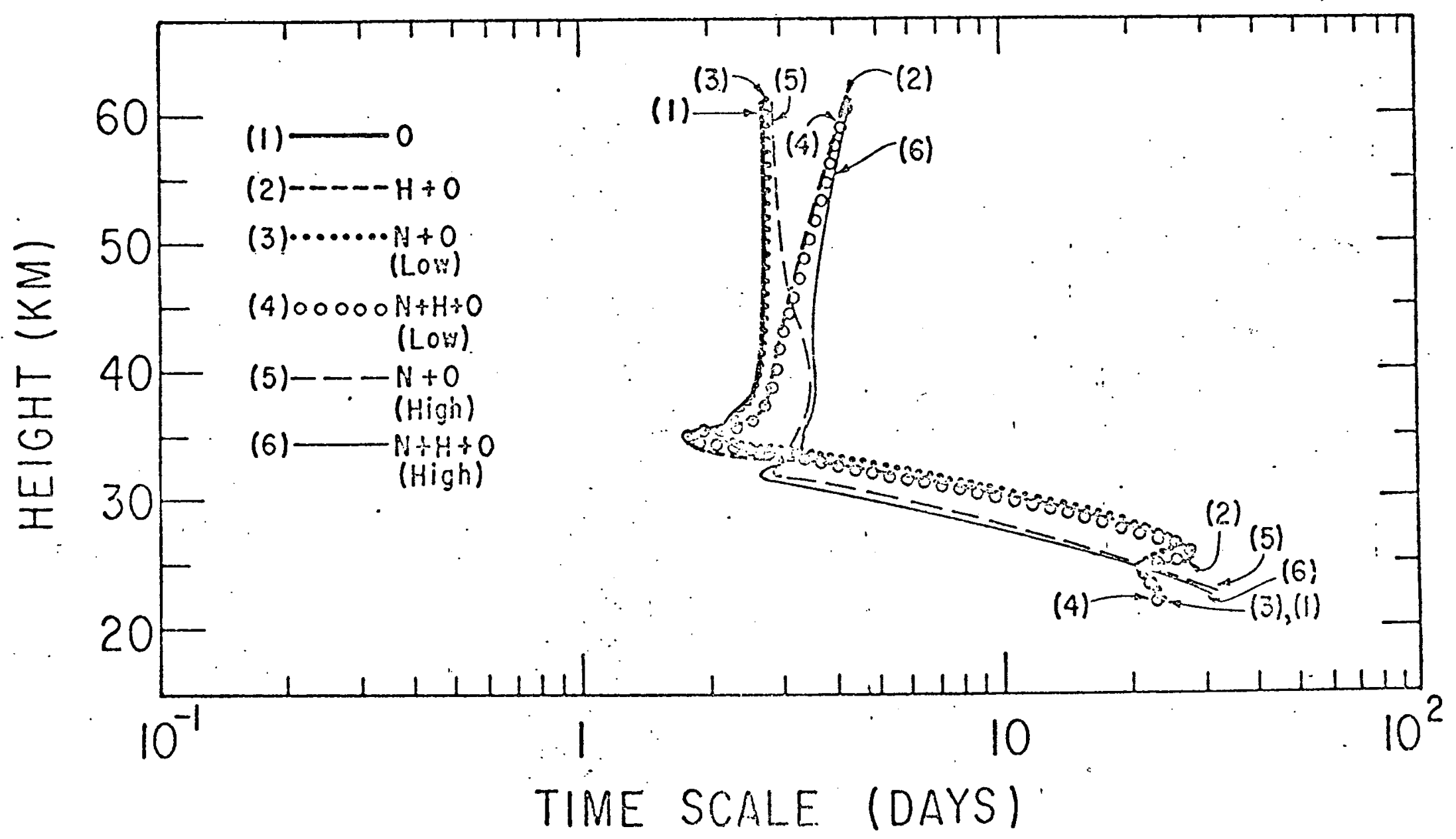




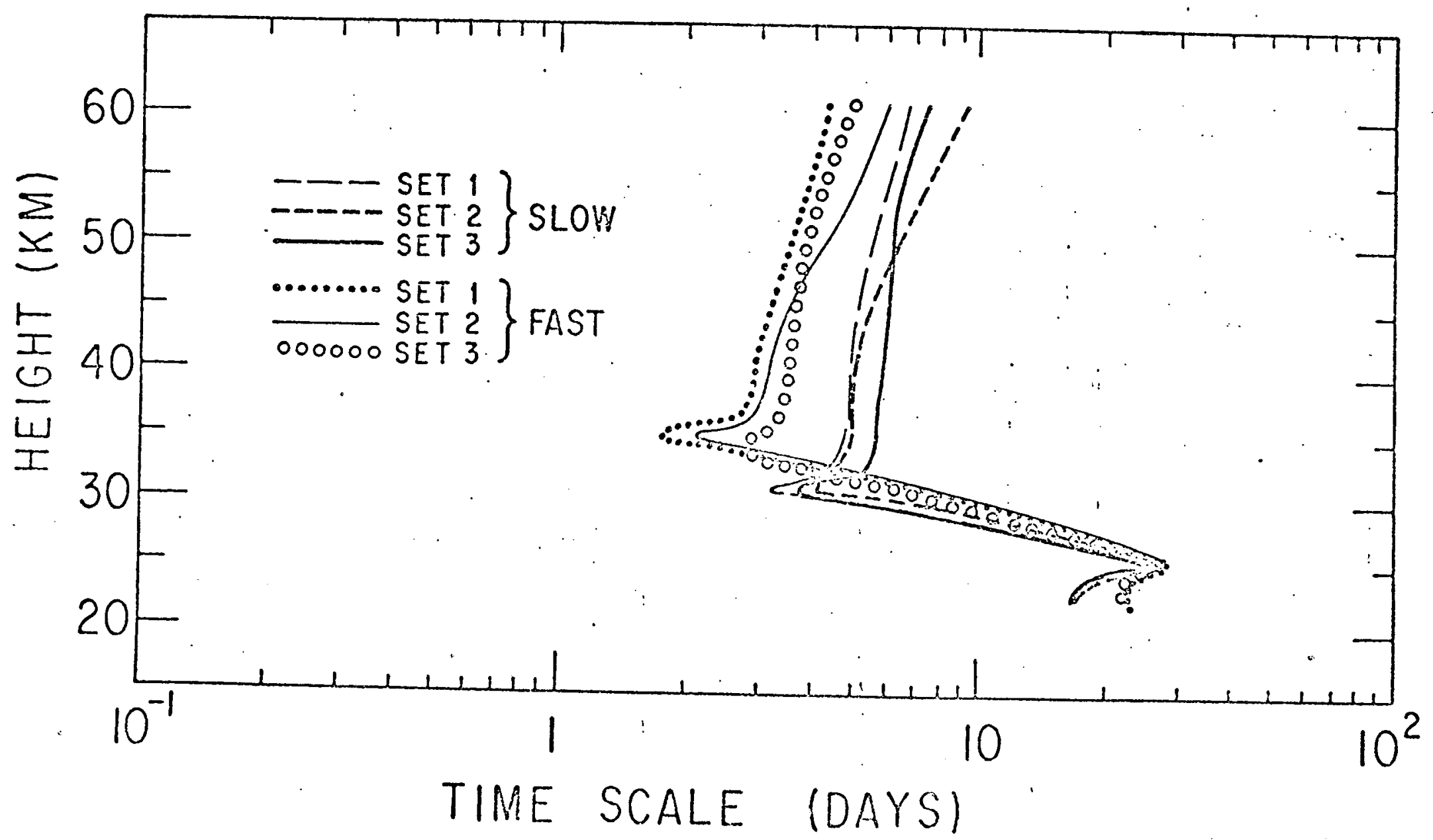

